Document downloaded from:

http://hdl.handle.net/10251/51029

This paper must be cited as:

Sánchez Tovar, R.; Leiva García, R.; García Antón, J. (2015). Characterization of thermal oxide films formed on a duplex stainless steel by means of confocal-Raman microscopy and electrochemical techniques. Thin Solid Films. 576:1-10. doi:10.1016/j.tsf.2014.12.024.

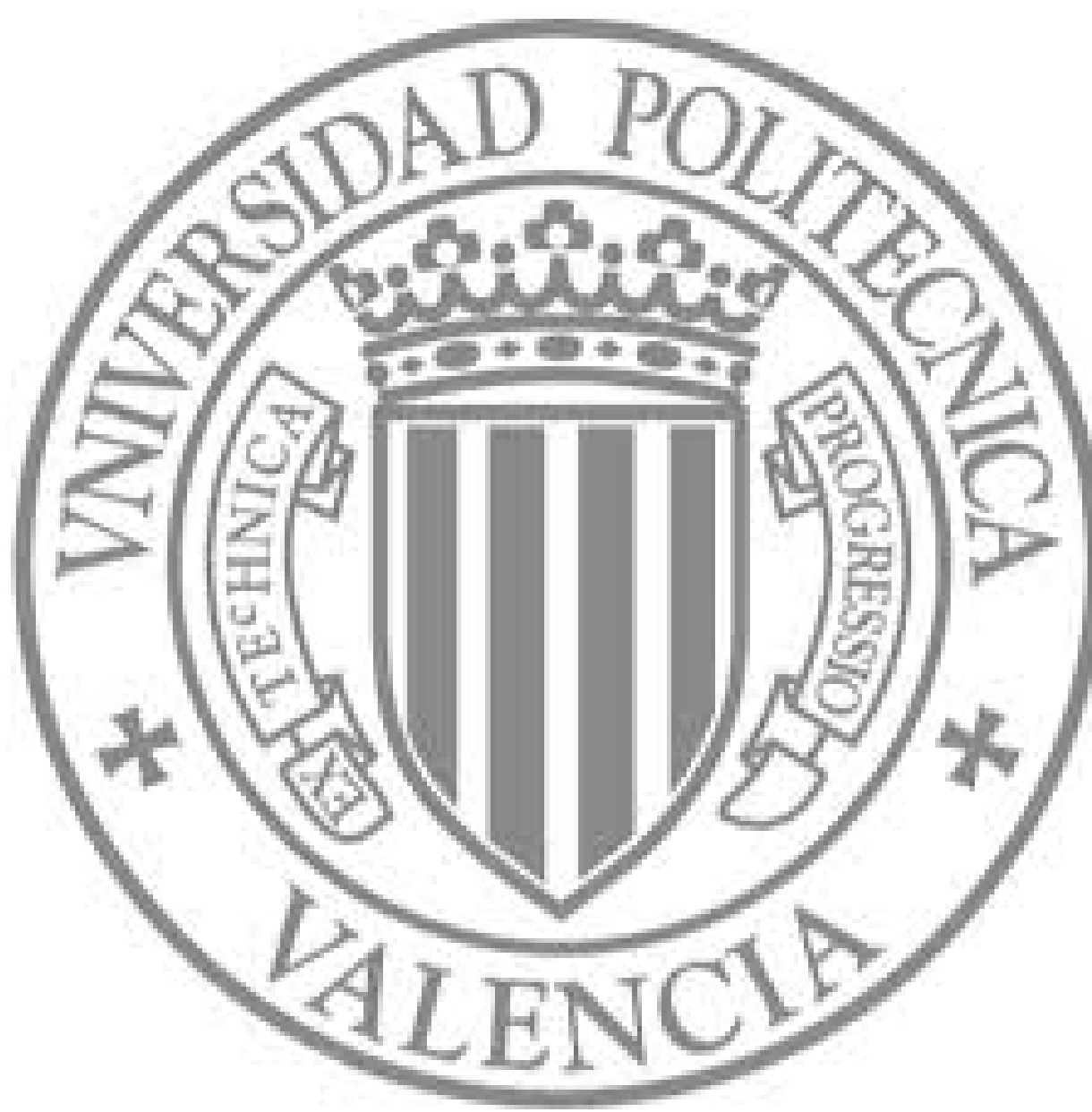

The final publication is available at

http://dx.doi.org/10.1016/j.tsf.2014.12.024

Copyright Elsevier 


\title{
Characterisation of thermal oxide films formed on a duplex stainless steel by means of confocal-Raman microscopy and electrochemical techniques
}

\author{
R. Sánchez-Tovar ${ }^{\mathrm{a}}$, R. Leiva-García ${ }^{\mathrm{a}, \mathrm{b}}$, J. García-Antón ${ }^{\mathrm{a}, *}$ \\ ${ }^{a}$ Ingeniería Electroquímica y Corrosión. Dpto. Ingeniería Química y Nuclear. \\ Universitat Politècnica de València. C/ Camino de Vera s/n. 46022 Valencia, Spain. \\ jgarciaa@iqn.upv.es \\ ${ }^{\mathrm{b}}$ School of Materials, University of Manchester, Manchester M13 9PL, UK
}

\begin{abstract}
In this work oxide films have been developed on the surface of a duplex stainless steel (UNS 1.4462) using high temperature confocal microscopy to follow their growth. The characteristics of these oxide films have been analysed by means of weight-gain measurements, Raman microscopy and electrochemical techniques, namely potentiodynamic polarisation curves and electrochemical impedance spectroscopy. The results show an increase in the amount of oxides (particularly $\gamma-\mathrm{Fe}_{2} \mathrm{O}_{3}$ and $\mathrm{Fe}_{3} \mathrm{O}_{4}$ ) with temperature. Regarding the electrochemical properties of these films, the corrosion resistance of the film tends to be lower with the heat treatment temperature, probably due to a more porous and heterogeneous scale. Mott Schottky plots show the n-type semiconductive behaviour of the films with donor densities that decrease with the enhancement of the temperature.
\end{abstract}

Keywords: Stainless Steel; EIS; Raman Spectroscopy; Confocal Laser Microscopy; Oxidation; Passivity. 


\section{Introduction}

Duplex stainless steels (DSSs) are balanced with two phases, ferrite and austenite. DSSs are increasingly used because of their outstanding properties [1, 2]. For example, DSS high-mechanical strength, resulting from the balance of the duplex phases, allows its use in light-weight components, or DSS high resistance to both general and localised corrosion (especially to pitting and crevice corrosion in chloride-containing media) due to high chromium and molybdenum contents. Therefore, the attractive combination of high strength, wide range of corrosion resistance, moderate weldability would seem to offer great potential for use of DSS in the industry, some of the main applications are: pulp and paper industry, desalination plants, cargo tanks and pipe systems in chemical tankers, seawater systems, firewalls and blast walls on offshore platforms, bridges, pressure vessels and heat exchangers. This means that the DSS can be found in many different shapes depending on the application, so, it can be machined by means of different procedures, some of them being done in hot working operations in oxidising environments.

High temperature oxidation of austenitic and ferritic stainless steels has been widely investigated [3-7]. However, only a few papers have studied the oxidation of DSSs [8, 9]. After casting, DSSs are subjected to different heat treatments in order to facilitate subsequent hot forming. Oxide films grow on the top of the free surfaces of DSSs during heating operations such as hot rolling or other hot working operations. In these operations, steels can be heated during a few hours in an oxidizing atmosphere in a wide range of temperatures arriving at temperatures above $1000^{\circ} \mathrm{C}$. Therefore, the resulting oxide should be completely removed after the hot working operations to avoid detrimental effects on the final product [10-12]. One improper sequence of heating or cooling during the hot working operations can lead to an increase in these detrimental 
effects because the resulting oxide films and chromium depleted layers greatly affect the corrosion resistance or the surface of the end product [13].

Therefore, the aim of the present work was to study the different phases of oxide growth on a DSS with temperature in the presence of air by means of high temperature confocal microscopy and Raman spectroscopy. Weight loss measurements were performed to quantify the amount of oxide deposition. Additionally, the electrochemical properties of the oxide film were studied by means of electrochemical methods, such as potentiodynamic curves, electrochemical impedance spectroscopy (EIS) and capacitance measurements.

\section{Experimental procedure}

\subsection{Materials}

The material used was a DSS, Alloy 900 (UNS 1.4462), the composition in weight is: $22.34 \% \mathrm{Cr}, 4.85 \% \mathrm{Ni}, 1.59 \% \mathrm{Mn}, 0.35 \% \mathrm{Si}, 2.69 \% \mathrm{Mo}, 0.13 \% \mathrm{Cu}, 67.80 \% \mathrm{Fe}, 0.02$ $\% \mathrm{P}, 0.03 \% \mathrm{C}, 0.20 \% \mathrm{~N}$, and $0.01 \% \mathrm{Ti}$. The electrodes of Alloy 900 were machined and cylindrically shaped (5 $\mathrm{mm}$ in diameter, $5 \mathrm{~mm}$ in thickness).

\subsection{In-situ Heat Treatments}

Before the heat treatments, the samples were wet abraded with silicon carbide paper up to \#4000, polished with alumina of 1 micron, rinsed with water and ethanol, and dried with hot air. Then, the samples were put in the crucible on the "Linkam" heating stage. Prior to heating, an air flow passed through the heating stage for 30 minutes in order to create an oxidising atmosphere; during the tests the air stream was maintained. Then, a heating ramp was programmed from $25^{\circ} \mathrm{C}$ to $700{ }^{\circ} \mathrm{C}, 800{ }^{\circ} \mathrm{C}$ and $900{ }^{\circ} \mathrm{C}$, respectively; 
these temperatures were maintained for 2 hours and images of the surface evolution were recorded on-line using a laser scanning confocal microscope "Olympus LEXT 3100". The mass of all specimens before and after oxidation was measured using an analytical balance "Mettler Toledo XP 56". After that, in order to identify the oxides formed during heating, the materials were examined by Raman spectroscopy (Witec Raman microscope, ALPHA300 M+) after the heat treatments. Excitation was provided by a He-Ne high power laser $(632 \mathrm{~nm})$ and a long distance objective at 500x was used for in situ measurements. Laser power was $0.5 \mathrm{~mW}$. Detection was achieved with a cooled charge coupled device (CCD) detector. Acquisition and basic treatment of spectra were performed with WITec Control software. Finally, the morphological changes in the microstructure were analysed using scanning electron microscopy operated at $10 \mathrm{kV}$ (SEM, JEOL JSM6300) and backscattered electrons (BSE).

\subsection{Electrochemical tests}

The electrochemical measurements were conducted in a $1 \mathrm{mM} \mathrm{NaCl}$ solution using an Autolab PGSTAT302N potentiostat. The reason for using this solution is to obtain results which can be comparable with the characterisation of the formed oxide scales with electrochemical localised techniques, which will be addressed in future papers; these localised techniques (Scanning vibrating electrode or scanning electrochemical microscopy) require diluted solutions to increase the spatial resolution. A silver/silver chloride $(\mathrm{Ag} / \mathrm{AgCl}, 3 \mathrm{M} \mathrm{KCl})$ and a platinum wire electrode served as the reference and counter electrodes, respectively. Polarisation curves of Alloy 900 were performed at the different temperatures. Polarisation tests began at a potential value of $-50 \mathrm{mV}_{\mathrm{Ag} / \mathrm{AgCl}}$ with respect to the open circuit potential (OCP) and the potential was subsequently scanned anodically to $1.5 \mathrm{~V} \mathrm{Ag} / \mathrm{AgCl}$ at a scanning rate of $0.5 \mathrm{mV} / \mathrm{s}$. 
EIS experiments were conducted over a frequency range from $100 \mathrm{kHz}$ to $10 \mathrm{mHz}$ with a $10 \mathrm{mV}$ (peak to peak) signal amplitude. Mott-Schottky plots were subsequently obtained by sweeping the potential from $0.5 \mathrm{~V} \mathrm{Ag} / \mathrm{AgCl}$ in the negative direction with potential steps of $100 \mathrm{mV}$ with an amplitude signal of $10 \mathrm{mV}$. A high scanning rate was used to avoid electroreduction of the film and changes in film thickness during the measurements. At a sufficiently high scanning rate, the defect structure within the film is "frozen-in", which avoids the defect density from being affected by potential [14-16]. A value of $5 \mathrm{kHz}$ has been used in this work to eliminate capacitance dependence on frequency since tests performed on the system used demonstrated that the capacitance becomes almost independent of frequency at approximately $5 \mathrm{kHz}$.

\section{Results and discussion}

\subsection{In-situ heat treatments}

Figures 1 to 3 show images of Alloy 900 surface at different stages of the heat treatment at $700{ }^{\circ} \mathrm{C}, 800{ }^{\circ} \mathrm{C}$ and $900{ }^{\circ} \mathrm{C}$, respectively. During all heating ramps (between $25^{\circ} \mathrm{C}$ and $700{ }^{\circ} \mathrm{C}$ ), the oxidation of the specimen was imperceptible below $300{ }^{\circ} \mathrm{C}$ (Figures 1a-b, 2a-b and $\mathbf{3}$ a-b). From this temperature up, the ferrite phase began to oxidise, presenting a brownish colour above $450{ }^{\circ} \mathrm{C}$ (Figures 1c, 2c and 3c). When increasing temperature up to $600{ }^{\circ} \mathrm{C}$, the ferrite phase completely oxidised and the austenite phase began to oxidise (Figures 1d, 2d and 3d). Therefore, in steels with two phases, surface oxidation is sequential, taking place first in one of the phases and then in the other.

During isothermal heating at $700{ }^{\circ} \mathrm{C}$ (Figures 1f to 11), the two phases continued oxidising, the growth of the oxide scale and the change in the products produce 
differences in colour between the two phases, red brown for ferrite and blue for austenite. These differences in colour of the scales, depending on the nature of the phase may be due to the fact that the oxide scale grows greater in the austenitic phase than in the ferritic phase.

Regarding the heat treatments at $800{ }^{\circ} \mathrm{C}$, two steps can be pointed out, namely the heating ramp between $700{ }^{\circ} \mathrm{C}$ and $800{ }^{\circ} \mathrm{C}$ and isothermal heating at $800{ }^{\circ} \mathrm{C}$ during 2 hours. In the first step (Figures $2 \mathbf{e}$ and $\mathbf{2 f}$ ) both phases remain darkening as a consequence of the oxidation process. By contrast, during the first ten minutes of isothermal heating (Figures $\mathbf{2 f}$ and $\mathbf{2 g}$ ) the ferrite becomes dark reddish-brown and the austenite dark green. After that (Figures $\mathbf{2 h}$ to $\mathbf{2 l}$ ), the amount of ferrite decreases and the colour of most of the sample becomes bright blue. This decrease in ferrite oxides can be related with the drop in the ferrite phase as a consequence of the formation of new intemetallic phases [17-19].

Finally, at times beyond one hour of heat treatment, the formation of nodules could be observed at $900{ }^{\circ} \mathrm{C}$, this formation being greater with the extension of the oxidation time. One of the consequences of the presence of nodules was irregular thickness of the oxide film [9]. This morphology presented more defects, which may increase susceptibility to corrosion. The formation of nodules at this temperature was due to the breakaway oxidation of the Cr-depleted layer when the external oxide scale was broken, the thickness of the oxide becoming irregular. Oxide scales enriched in iron and depleted in chromium are brittle and tend to break under thermal stress [7, 20]. According to the literature the formation of nodules is greater on the austenite phase [9]. The chromium content in ferrite is higher than in austenite, so a thin and dense chromium oxide-enriched film preferentially forms in ferrite and this film prevents the underlying metal from further oxidation. On the other hand, the chromium content in 
austenite is comparatively lower; the produced scale is thicker and less protective for the underlying metal. As a result oxidation takes place and the nodules appear [9].

\subsection{Mass gain tests}

Figure 4 shows the weight gain per unit of area of Alloy 900 oxidised in air at different temperatures. It can be observed that the weight gain was doubled with the increase in heating temperature. Therefore, oxide growth is strongly dependent on temperature. On the other hand, all the observed scales formed at all the temperatures adhered to the steel.

\subsection{Raman spectroscopy analysis}

The oxide scales formed on DSSs can be classified into external and internal oxide scales. The former is composed of the same phases, $\mathrm{Fe}_{3} \mathrm{O}_{4}, \mathrm{Fe}_{2} \mathrm{O}_{3}$ and $(\mathrm{Fe}, \mathrm{Cr})_{3} \mathrm{O}_{4}$, whereas the latter is richer in chromium oxides [9]. Figure 5 shows the Raman spectra obtained by spotting a laser beam at these regions on the oxide film produced on Alloy 900 heated at $700{ }^{\circ} \mathrm{C}, 800{ }^{\circ} \mathrm{C}$ and $900{ }^{\circ} \mathrm{C}$ in air during 120 minutes. The different colours observed on these regions are related to the oxides present on Alloy 900 phases and their concentration.

Two areas were clearly observed in Alloy 900 heated for 2 hours at $700{ }^{\circ} \mathrm{C}$, corresponding to the two phases presented on the Alloy: ferrite and austenite. In this case, the orange colour is associated with the ferrite phase and the blue one with austenite. Figure 5a shows the spectrum obtained in the orange area, where three strong peaks, located at 540, 650 and $680 \mathrm{~cm}^{-1}$, respectively can be observed. According to the two last peaks the iron oxides on the orange region can be identified as a mixture of $\gamma$ $\mathrm{Fe}_{2} \mathrm{O}_{3}$ and $\mathrm{Fe}_{3} \mathrm{O}_{4}[21,22]$, whereas the peak at $540 \mathrm{~cm}^{-1}$ may correspond to the chromium oxides [23]. On the other hand, the spectrum on the blue area (Figure 5b) 
presents two strong peaks at 560 and $680 \mathrm{~cm}^{-1}$, which are related with magnetite $\left(\mathrm{Fe}_{3} \mathrm{O}_{4}\right)$ [24] and one peak at $645 \mathrm{~cm}^{-1}$, which could be related to the presence of $\gamma-\mathrm{Fe}_{2} \mathrm{O}_{3}$ [21]; no peaks related with chromium compounds are observed.

Two different spectra can also be identified in the samples heated at $800{ }^{\circ} \mathrm{C}$. The first spectrum (Figure 5c) was obtained spotting the laser on the blue area (ferrite phase in this case), giving three clear peaks at 540,650 and $680 \mathrm{~cm}^{-1}$. According to the literature $[25,26]$ these peaks indicate the presence of iron and chromium oxides. On the other hand, the spectrum on the dark phase (Figure 5d), which can be identified as austenite, presents two strong peaks at 560 and $680 \mathrm{~cm}^{-1}$ associated with the presence of magnetite [24] and one peak at $645 \mathrm{~cm}^{-1}$ related to the presence of $\gamma-\mathrm{Fe}_{2} \mathrm{O}_{3}$ [21]. Additionally, there are two peaks at 350 and $540 \mathrm{~cm}^{-1}$ which could be related with $\mathrm{Cr}_{2} \mathrm{O}_{3}$ [27]; however the intensity of these peaks is low compared with the intensity of the peaks related to magnetite.

Finally, only one spectrum was observed after spotting the laser on different points of the sample heated at $900{ }^{\circ} \mathrm{C}$ (Figure 5e). Strong peaks can be observed at 560 and 680 $\mathrm{cm}^{-1}$, which are related to the presence of magnetite [24] and one peak at $645 \mathrm{~cm}^{-1}$ which could be related with the presence of $\gamma-\mathrm{Fe}_{2} \mathrm{O}_{3}$ [21]. Again, two additional peaks can be observed at 350 and $540 \mathrm{~cm}^{-1}$ which are related with $\mathrm{Cr}_{2} \mathrm{O}_{3}$ [27].

Despite the fact that chromium oxides can be detected in the scale formed on the austenite phase at $800{ }^{\circ} \mathrm{C}$ and on the oxide scale formed over the entire surface at 900 ${ }^{\circ} \mathrm{C}$, the relative intensity of the peaks compared with the intensity of the magnetite peaks is low. Then, the content of magnetite may be comparatively higher than the content of $\mathrm{Cr}_{2} \mathrm{O}_{3}$. 
Therefore, the presence of $\mathrm{Fe}_{3} \mathrm{O}_{4}$ increases with temperature in the oxides formed on the Alloy 900 surface. The increase in the oxidation temperature results in an increase of iron oxides on the surface [9]. Furthermore, the presence of chromium oxides is better observed in the ferrite than in the austenite phase.

\subsection{SEM analysis}

SEM images of the morphology of the samples using BSE were obtained in order to establish the percentage of the different phases in the steel after the heat treatments. Figure 6 shows micrographs obtained by SEM and BSE for polished Alloy 900 at different heat treatment temperatures. Austenite $(\gamma)$, the light phase, and ferrite $(\alpha)$, the dark phase, are visible in all the images. The sigma Phase $(\sigma)$ can be distinguished in the backscattered images of the microstructures of Alloy 900 heated at $800{ }^{\circ} \mathrm{C}$ and $900{ }^{\circ} \mathrm{C}$ during 2 hours. The sigma phase looks brighter than the surrounding matrix owing to its higher Mo content compared with austenite and ferrite. The size and number of precipitates increase with increasing temperature and time. For the Alloy heat-treated at $800{ }^{\circ} \mathrm{C}$, the fraction of the sigma phase is significantly increased due to the decomposition of the ferrite phase into sigma and secondary austenite phases [11-13]. This decrease is coincident with the behaviour observed in the in-situ images obtained at $800^{\circ} \mathrm{C}$ where, a decrease in the percentage of the ferrite phase was observed.

\subsection{Electrochemical measurements}

\subsubsection{Polarisation curves}

Figure 7 shows the potentiodynamic polarisation curves of Alloy 900 after the different heat treatments. It is noteworthy that the heating treatment hinders passivation; i.e., the existence of the passive region diminishes with temperature and disappears at $900{ }^{\circ} \mathrm{C}$. 
Therefore, according to the polarisation curves the heat treatments modify the film formed on the Alloy surface, generating a less protective film from the corrosion point of view.

\subsubsection{EIS measurements}

In order to analyse the changes caused by the heat treatment on the films formed on the Alloy 900 samples, EIS were performed at OCP.

Figure 8 shows the Nyquist (Figure 8a) and Bode-phase (Figure 8b) plots versus immersion time in the $\mathrm{NaCl}$ solution. The electrochemical impedance spectra of the Nyquist plots reveal a somewhat unfinished capacitive arc, which is temperature dependant as evidenced by the sharp decrease of impedance values with temperature. This behaviour is consistent with a loss of protection against corrosion as temperature increases during heat treatment. Bode-phase plot depicts two time constants, at highand low-frequencies. This feature is often considered as the response of a non-homogeneous film composed of a compact inner layer, known as barrier layer, and a less compact (porous) outer layer. For stainless steels, such as Alloy 900 it is generally accepted that the inner layer is mainly composed of chromium and iron oxides, the former being the major contributor to passivation. The outer layer is assumed to be composed of iron oxides and hydroxides [28, 29].

The stability of the system is crucial for the validity of EIS measurements. KramersKronig $(\mathrm{K}-\mathrm{K})$ transforms can be used as an independent validity check of the impedance data (that is, compliance of the system with the constraints of the Linear Systems Theory (LST)) [30-32]. K-K transforms have been applied to the experimental impedance data by transforming the real axis into the imaginary axis and the imaginary 
axis into the real axis and then comparing the transformed quantities to their respective experimental data. As an example, typical $\mathrm{K}-\mathrm{K}$ transforms of the impedance data obtained in the sample heated at $700{ }^{\circ} \mathrm{C}$ are displayed in Figure 9. Figure 9 shows similar results to those obtained between the experimental points and the corresponding $\mathrm{K}-\mathrm{K}$ transforms, confirming the compliance of the system with the LST.

Figure 10 shows the equivalent electric circuit used to interpret EIS spectra of the films formed on the Alloy 900 samples. This equivalent circuit has been usually employed to interpret EIS spectra of passive films having a two-layer structure [33-35], which is the case of Alloy 900. In the proposed model, $R_{S}$ corresponds to the resistance of the electrolyte, and $R_{1}, C P E_{1}$ and $R_{2}, C P E_{2}$ to the resistance and capacitance of the outer porous layer and the inner barrier layer, respectively. The sum of $R_{1}+R_{2}$ is defined as the polarisation resistance, $R_{p}$, and is related to the corrosion resistance of the metal.

A constant-phase element (CPE) representing a shift from the ideal capacitor behaviour was used instead of the capacitance itself. CPEs are used to model frequency dispersion behaviour corresponding to different physical phenomena such as surface heterogeneity resulting from surface roughness, impurities, dislocations, formation of porous layers, and so on [35-37]. The impedance of a CPE is defined as:

$$
\mathrm{Q}=\mathrm{Z}_{\mathrm{CPE}}=\left[\mathrm{C}(\mathrm{jw})^{\alpha}\right]^{-1}
$$

where $\alpha$, defined as a CPE power, lies between -1 and 1 . When $\alpha=1$ the CPE describes an ideal capacitor; for $\alpha=0$ the CPE is an ideal resistor; for $\alpha=0.5$ the CPE represents a Warburg diffusional impedance and for $0.5<\alpha<1$ the CPE describes a frequency dispersion of time constants due to local heterogeneities in the dielectric material. A pure inductance yields $\alpha=-1$. 
Additionally, the CPE of each subcircuit has been converted into a pure capacitance (C) using equations $2[38,39]$ and $3[40,41]$.

$$
\begin{gathered}
C_{1}=Q_{1}^{1 / \alpha_{1}}\left(R_{S}^{-1}+R_{1}^{-1}\right)^{\left(\alpha_{1}-1\right) / \alpha_{1}} \\
C_{2}=\frac{\left(Q_{2} \cdot R_{2}\right)^{1 / \alpha_{2}}}{R_{2}}
\end{gathered}
$$

where $\mathrm{Q}=\mathrm{Z}_{\mathrm{CPE}}($ Equation (1)).

Table 1 shows the parameters obtained for the proposed circuit. Chi-squared $\left(\chi^{2}\right)$ values were used to evaluate the quality of data fitting to the proposed equivalent circuit. $\chi^{2}$ values were of a magnitude order of $10^{-3}$ or lower indicating the suitability of the circuit. This is also shown in Figure 8, where the simulated data are shown as solid lines.

Resistance at very high frequencies corresponds to the uncompensated resistance of the solution, which, according to Table 1, remains almost constant in all tests. In fact, at high frequencies $\left(10^{4}-10^{5} \mathrm{~Hz}\right)$, the absolute impedance curve is almost independent of frequency with a phase angle of $0^{\circ}$, indicating that $R_{\mathrm{S}}$ is almost constant $\left(R_{\mathrm{S}} \cong 1 \mathrm{k} \Omega \cdot \mathrm{cm}^{2}\right)$. Table 1 also shows $R_{l}$, which strongly depends on the existence of pores or defects into which the electrolyte can penetrate; thus, $R_{1}$ provides a sensitive indication of the appearance of defects in the passive film. $R_{l}$ values are very low and close to $R_{\mathrm{s}}$, indicating that $R_{1}$ might correspond approximately to the resistance of the electrolyte inside the pores [28]. However, the value of $R_{l}$ for the sample heated at $900{ }^{\circ} \mathrm{C}$ is significantly higher than the resistances of the other electrodes. This could be related with the great amount of iron oxides formed on the Alloy surface during the heat treatment (see Figures 3, 4 and 5). In fact, Raman spectrum of the scales formed at 900 ${ }^{\circ} \mathrm{C}$ showed the highest $\mathrm{Fe}_{3} \mathrm{O}_{4}$ amount (Figure 5). Nevertheless, the value of $\alpha_{1}$ for this 
case is the lowest (0.42) and indicates that, in spite of having a low $C_{1}\left(0.28 \mu \mathrm{F} \mathrm{cm}{ }^{-2}\right)$, diffusion processes and the number of defects are enhanced. Furthermore, the presence of nodules at $900{ }^{\circ} \mathrm{C}$ might also increase the number of defects on the Alloy surface (Figure 3). On the other hand, $\alpha_{1}$ values decrease with temperature, which confirms that temperature produces defects and pores on the formed films [42]. The evolution observed in $\alpha_{1}$ suggests that the film becomes more defective as temperature increases. Pan [28] has associated this tendency with the formation of a more porous film that generates a larger effective area and thus, lower capacitance values are determined as temperature increases.

As regards the parameters of the inner oxide film, Table 1 shows that both $\alpha_{2}$ and $R_{2}$ decrease with temperature, indicating that temperature modifies the films formed on the Alloy, decreasing their corrosion resistance and increasing the number of defects. Additionally, the lowest $C_{2}$ values are obtained at the lowest temperatures.

The electrical parameters obtained reveal that $R_{2}$ is significantly greater than the values associated with $R_{1}$, which indicates that the protection provided by the passive film was predominantly due to the barrier layer [28, 43].

Polarisation resistances follow the same tendency as the resistance of the inner layer, i.e. they decrease with temperature. Therefore, temperature affects the thin chromium oxide layer with high passive characteristics. In this way, the lowest $R_{p}$ values correspond to Alloy 900 heated at $900{ }^{\circ} \mathrm{C}$. This is in agreement with the higher austenite content in this sample (Figure 3), since austenite is the phase with a lower chromium content compared to ferrite and this fact could explain the worse corrosion behaviour of the samples heated at $900{ }^{\circ} \mathrm{C}$. 


\subsubsection{Capacitance measurements}

The electrochemical capacitance of the passive film/electrolyte interface was measured as a function of the applied potential to assess the semiconducting properties of the films formed on Alloy 900. Since the space charge region developed in the passive film and the Helmholtz layer can be considered as two capacitors in series, the measured capacitance of the film/electrolyte interface can be expressed as [44]:

$$
\frac{1}{C}=\frac{1}{C_{S C}}+\frac{1}{C_{H}}
$$

where $C_{S C}$ is the capacitance of the space charge layer and $C_{H}$ the capacitance of the Helmholtz layer.

It is generally accepted that the capacitance of the space charge layer is very small compared with that of the Helmholtz layer and the measured interfacial capacitance can be regarded as that of the space charge layer when the potential perturbations are applied with a sufficiently high frequency [45, 46]. However, several studies $[47,48]$ have shown that a significant part of the potential difference at the semiconductor/electrolyte interface extends to the Helmholtz layer in the solution. Therefore, $C_{H}$ should not be neglected. In this way, the space charge capacitance of pand n-type semiconductors is given by Equations 5 and 6, respectively [44, 47, 49].

$$
\begin{array}{ll}
\frac{1}{C^{2}}=\frac{1}{C_{H}^{2}}+\frac{2}{\varepsilon \varepsilon_{0} e N_{D}}\left(E-E_{F B}-\frac{k T}{e}\right) & \text { n-type } \\
\frac{1}{C^{2}}=\frac{1}{C_{H}^{2}}-\frac{2}{\varepsilon \varepsilon_{0} e N_{A}}\left(E-E_{F B}-\frac{k T}{e}\right) & \text { p-type }
\end{array}
$$


where $\varepsilon$ is the dielectric constant of the passive film (a value of 15.6 has been assumed for the chromium and iron oxides formed on stainless steels $[49,50], \varepsilon_{0}$ is the vacuum permittivity $\left(8.85 \cdot 10^{-14} \mathrm{~F} / \mathrm{cm}\right), e$ is the electron charge $\left(1.60 \cdot 10^{-19} \mathrm{C}\right), N_{D}$ and $N_{A}$ are the donor and acceptor densities, respectively, $E_{F B}$ is the flat-band potential $k$ is the Boltzmann constant $\left(1.38 \cdot 10^{-23} \mathrm{~J} / \mathrm{K}\right)$ and $T$ is the absolute temperature.

Figure 11 shows the plot of $C^{-2}$ vs potential, $E$, (Mott-Schottky plots) for the films formed on Alloy 900 at different temperatures. Mott-Schottky plots clearly reveal the existence of two regions in the films formed after the heat treatments, where two linear relationships appear with positive and negative slopes between $C^{-2}$ and $E$ (Regions I and II). The positive slope of the Mott-Schottky plot at lower potentials in the passive region, indicates that the thermal oxide layers formed behave like n-type semiconductors $[51,52]$; this is associated with an outer oxide film mainly composed of $\gamma-\mathrm{Fe}_{2} \mathrm{O}_{3}$ and $\mathrm{Fe}_{3} \mathrm{O}_{4}$ iron oxides (which is in agreement with the confocal laser scanning and Raman spectroscopy analysis) and an inner layer containing chromium oxides. Region II is characterised by a decrease in the Mott-Schottky plots. This feature has been usually explained in terms of a strong dependence of Faradaic current on potential in the transpassive region. In this region, a modification in the electronic properties of the passive film from n-type to p-type semiconductivity is related to an increase in the conductivity of the film due to the solid state oxidation of $\mathrm{Cr}$ (III) to $\mathrm{Cr}$ (VI) and the change in semiconductivity behaviour can be explained by the generation of cation vacancies (electronic acceptors and p-type dopants) at the film/solution interface [5255]. This is consistent with the polarisation curves, in which the transpassive region of the heated samples was close to $0.5 \mathrm{~V}_{\mathrm{Ag} / \mathrm{AgCl}}$. 
From the positive slopes of the linear zones in Figure 11, $N_{D}$ can be calculated for ntype semiconductors using Equation 5. For stainless steels, possible donors in the oxide structure are mainly cation interstitials, such as $\mathrm{Fe}^{2+}$ metal ions, and oxygen vacancies $[46,56,57]$. Table 2 shows the values of $\mathrm{N}_{\mathrm{D}}$ for Alloy 900 at the different heating temperatures. In all cases, $\mathrm{N}_{\mathrm{D}}$ values are of the order of $10^{20}$, according to the results of other authors for stainless steels $[45,58,59]$. It is remarkable that the $N_{D}$ values significantly decrease in the films formed at $900{ }^{\circ} \mathrm{C}$. Ferreira also obtained lower $N_{D}$ values when the temperature of film formation increased [60]. As magnetite is a mixture of $\mathrm{Fe}_{2} \mathrm{O}_{3}$ and $\mathrm{FeO}$, its stoichiometry can vary from 0 to 0.5 ; then, the observed behaviour with temperature might be related to the formation of magnetite with a stoichiometry $\left(\mathrm{x}=\mathrm{Fe}^{2+} / \mathrm{Fe}^{3+}\right)$ closer to 0 than to 0.5 when the samples are heated at 900 ${ }^{\circ} \mathrm{C}[61]$. Several authors have also suggested that small changes in stoichiometry modify magnetite conductivity by several orders of magnitude and influence redox reactivity [62-64]. Therefore, when samples are heated at $900{ }^{\circ} \mathrm{C}$, the magnetite (which is the main oxide on the steel surface) oxidises, decreasing the percentage of $\mathrm{Fe}^{2+}$ and the number of donors. However, this fact does not mean that the number of defects in the passive film formed at $900{ }^{\circ} \mathrm{C}$ decreases. Contrarily, as oxygen vacancies may be assumed as electron donors $[65,66]$, a decrease in $N_{D}$ for the films formed at $900{ }^{\circ} \mathrm{C}$ might be related to two factors: first, an increase in the thickness of the formed oxide film, corroborated by the high $C_{1}$ and $R_{1}$ values (Table 1) and the higher mass gain (Figure 5), and second, the oxidation of the magnetite, which changes the conductive properties of the oxides. In fact, the presence of donor vacancies prevents migration of cations from the substrate metal and penetration of harmful anions, such as $\mathrm{Cl}^{-}$, from the electrolyte, thereby improving corrosion resistance $[44,67,68]$. 


\section{Conclusions}

During the heat treatments, DSS is oxidised in a sequential way, first the ferrite and then the austenite phase, as a consequence of differences in their chemical composition. The oxides formed on the outer scale of the studied DSSs are mainly $\gamma-\mathrm{Fe}_{2} \mathrm{O}_{3}$ and $\mathrm{Fe}_{3} \mathrm{O}_{4}$, the percentage of the latter increasing with temperature. The presence of chromium oxides is more noticeable in the ferrite than in the austenite phase, but the formation of nodules at $900{ }^{\circ} \mathrm{C}$, which are related to the breakaway oxidation of the chromium depleted layer, is greater in the austenite phase.

The corrosion resistance properties of the films decrease with the heating temperature affecting the normal passivation properties of DSS in the presence of an electrolyte. The heat treatment increases the resistance and thickness of the oxide layer but also the number of defects and pores. Therefore, if the removal of the oxide film is not properly done on the entire surface after the hot work procedure, the risk of localised corrosion on service will increase.

Acknowledgments: We wish to express our gratitude to MICINN (CTQ2009-07518) (UPVO8-3E-012), to Universitat Politècnica de València (CEI-01-11), to the Generalitat Valenciana for its help in the CLSM acquisition (MY08/ISIRM/S/100), and to Dr. Asunción Jaime for her translation assistance. 


\section{References}

[1] T.H. Chen, K.L. Weng, J.R. Yang. The effect of high temperature exposure on the microstructural stability an toughness property in a 2205 duplex stainless steel. Mater. Sci. Eng A 338 (2002) 259-270.

[2] Ju. Li, Y. Xi, X. Xiao, J. Zhao, L. Jiang, J. Hu. A new resource-saving high manganese and nitrogen super-duplex stainless steel 25Cr-2Ni-3Mo-xMn-N. Mater. Sci. Eng A 527 (2009) 245-251.ic

[3] N. Otsuka, Y. Nishyama, T. Kudo. Breakaway oxidation of TP310S stainless steel foil initiated by $\mathrm{Cr}$ depletion of the entire specimen in a simulated fleu-gas atmosphere. Oxid. Met. 62 (2004) 121-139.

[4] S.Y. Cheng, S.L. Kuan, W.T. Sai. Effect of water wapor on annealing scale formation on 316 SS. Corros. Sci. 48 (2006) 634-649.

[5] R.L. Higginson, M.A.E. Jepson, G.D. West. Use of EBSD to characterize high temperature oxides formed on low alloy and stainless steels. Mater. Sci. Technol. 22 (2006) 1325-1332.

[6] M.A.E. Jepson, R.L. Higginson. The use of of EBSD to study the microstructural development of oxide scales on 316 stainless steels. Mater. High Temp 22 (2005) 195-200.

[7] I. Saeki, T. Saito, R. Furuichi, H. Konno, T. Nakamura, K. Mabuchi. Growth process of protective oxides formed on type 304 and 430 stainless steels at $1273 \mathrm{~K}$. Corros.Sci. 40 (1998) 1295-1302.

[8] Qiumin Jin, Jun Li, Yulai Xu, Xueshan Xiao, Wei Zhang, Laizhu Jiang. High temperature oxidation of duplex stainless steels S32101 and S32304 in air and simulated industrial reheating atmosphere. Corros.Sci. 52 (2010) 2846-2854.

[9] L.F. Li, Z.H. Jiang, Y. Riquier. High-temperature oxidation of duplex stainless steels in air mixed gas of air and CH4. Corros.Sci. 47 (2005) 57-68.

[10] M. Torres, R. Colas, A model for heat conduction through the oxide layer of steel during hot rolling. J. Mater. Process. Technol. 105 (2000) 258-263.

[11] Y.H. Li, C.M. Sellars. Cracking and deformation of surface scale during hot rolling of steel . Mater. Sci. Technol. 18 (2002) 304-311.

[12] P.A Munther, J.G. Lenard, The effect of scaling on interfacial friction in hot rolling of steels. J Mater. Process. Technol. 88 (1999) 105-113.

[13] M.E. Somervuori, L-S. Johansson, M.H. Heinonen, D.H.D. van Hoecke, N. Akdut, H.E. Hänninen. Characterisation and corrosion of spot welds of austenitic stainless steels. Materials and Corrosion 55 (2004) 421-436.

[14] Janusz Sikora, Elzbieta Sikora, Digby D Macdonald. The electronic structure of the passive film on tungsten. Electrochim. Acta 45 (2000) 1875-1883.

[15] KyungJin Park, SeJin Ahn, HyukSang Kwon. Effects of solution temperature on the kinetic nature of passive film on Ni. Electrochimica Acta 56 (2011) 16621669.

[16] Zhonglin Jiang, Xin Dai, Hugh Middleton. Investigation on passivity of titanium under steady-state conditions in acidic solutions. Materials Chemistry and Physics 126 (2011) 859-865.

[17] C.J. Park, V. Shankar Rao, H.S. Kwon. Effects of sigma phase on the initiation and propagation of pitting corrosion of duplex stainless steel, Corrosion 61 (2005) 76-83.

[18] D.Y. Kobayashi, S. Wolynec. Evaluation of Low Corrosion resistance phase formed During the Sigma Phase Precipitation in Duplex Stainless Steels. Mat. Res. 2 (1999) 239-247. 
[19] H. sieurin, R. Sandström. Sigma phase precipitation in duplex stainless steel 2005. Mater. Sci. Eng A A 444 (2007) 271-276.

[20] M. Schtze, Fundamentals of high temperature corrosion, in. R.W.Cahn, P. Haasen, E.J. Kramer (Eds.), Corrosion and Environmental Degradation, Wiley-VCH, Weinheim, 2000, p. 81.

[21] R.J. Thiberau, C.W. Brown, R.H. Heidersbach. Raman spectra of possible corrosion products on iron at 100 to $150{ }^{\circ} \mathrm{C}$ in air. Appl. Spectro. 32 (1978) 532535.

[22] D. Thierry, D. Persson, C. Leygraf, N. Boucherit, A. Hugot-Le Goff. Raman spectroscopy and XPS investigations of anodic corrosion films formed on Fe-mo alloys in alcaline solutions. Corros. Sci. 32 (1991) 273-284.

[23] D. Thierry, D. Persson, C. Leygraf, D. Delichere, S. Joiret, C. Pallota. In-situ Raman spectroscopy combined with X-ray photoelectron spectroscopy and nuclear microanalyisis for studies of anodic corrosion film formation on $\mathrm{Fe}-\mathrm{Cr}$ single crystals. J. Electrochem. Soc. 135 (1988) 305-310.

[24] J.R. Verble. Temperature-dependent light scattering studies of the Verwley transition and electronic disorder in magnetite. Phys Rev B 9 (1974) 5236-5248.

[25] M.Da Cunha Bel, M. Walls, N.E. Hakiki, J. Corset, E. Picquenard, G.Sagon. Composition structure and properties of the oxide films formed on the stainless steels 316L in a primary type PWR environment. Corros. Sci. 40 (1998) 447-463.

[26] I.R Beattie, T.R. Gilson. The single-crystal Raman spectra of nearly opaque materials. J. Chem. Soc. A (1970) 980-986.

[27] P. Fabis, R. Heindersbach, C. Brown, T. Rockett. Oxide scale formation on iron chromium alloys in elevated temperature air environments. Corrosion 37 (1981) 700-711.

[28] J. Pan, C. Leygraf, R.F.A. Jargelius-Pettersson, J. Linden. Characterization of High temperature oxide films on stainless steels by electrochemical-impedance spectroscopy. Oxid. Met, 50 (1998) 431-455.

[29] K. Jüttner. Electrochemical impedance spectroscopy (EIS) of corrosion processes on inhomogeneous surfaces. Electrochim. Acta 35 (1990) 1501-1508.

[30] B.Evgenij, J. Ros Macdonald, Impedance Spectroscopy: Theory, Experiment and Applications, $2^{\text {nd }}$ ed., West Sussex, UK, 2005.

[31] M. Urquidi - Macdonald, S. Real, D.D. Macdonald. Application of Kramers - Kronig Transforms in the Analysis of Electrochemical Impedance Data II. Transformations in the Complex Plane. J. Electrochem. Soc. 133 (1986) 20182024.

[32] M. Urquidi - Macdonald, S. Real, D.D. Macdonald. Applications of KramersKronig transforms in the analysis of electrochemical impedance data-III. Stability and linearity. Electrochim. Acta 35 (1990) 1559-1566.

[33] F. Mansfeld, H. Shih. Detection of pitting with electrochemical impedance spectroscopy. J. Electrochem. Soc., 135 (1988) 1171-1172.

[34] S. L. de Assis, S. Wolynec, I. Costa. Corrosion characterization of titanium alloys by electrochemical techniques. Electrochim. Acta, 51 (2006), 1815-1819.

[35] F.G. da Silva, J. B. Libardi Liborio A study of steel bar reinforcement corrosion in concretes with SF and SRH using electrochemical impedance spectroscopy. Mat. Res. 9 (2006) 209-215.

[36] P. Bommersbach, C. Alemany-Dumont, J.P. Millet, B. Normand. Formation and behaviour study of an environment-friendly corrosion inhibitor by electrochemical methods. Electrochim. Acta, 51 (2005), pp. 1076-1084. 
[37] M.E. Orazem, B. Tribollet Electrochemical Impedance Spectroscopy (first ed.) John Wiley and Sons, Hoboken, NJ (2008) (Chapter 13).

[38] B. Hirschorn, M.E. Orazem, B. Tribollet, V. Vivier, I. Frateur, M. Musiani. Determination of effective capacitance and film thickness from constant-phaseelement parameters. Electrochim. Acta, 55 (2010) 6218-6227.

[39] M. Metikoš-Huković, R. Babić, Z. Grubač, Ž. Petrović, N. Lajçi. High corrosion resistance of austenitic stainless steel alloyed with nitrogen in an acid solution. Corros. Sci. 53 (2011) 2176-2183.

[40] A. Kocijan, D. Kek Merl, M. Jenko. The corrosion behaviour of austenitic and duplex stainless steels in artificial saliva with the addition of fluoride. Corros. Sci., 53 (2011) 776-783.

[41] N.P. Cosman, K. Fatih, S.G. Roscoe. Electrochemical impedance spectroscopy study of the adsorption behaviour of a-lactalbumin and bcasein at stainless steel. J. Electroanal. Chem., 574 (2005) 261-271.

[42] J-H. Wang, C. C. Su, Z. Szklarska-Smialowska. Effects of Cl-Concentration and Temperature on Pitting of AISI 304 Stainless Steel. Corrosion, 44 (1988), 732737.

[43] R.M. Fernández-Domene, E. Blasco-Tamarit, D.M. García-García, J. GarcíaAntón. Thermogalvanic corrosion of Alloy 31 in different heavy brine $\mathrm{LiBr}$ solutions. Corros. Sci. 55 (2012) 40-53.

[44] N. E. Hakiki. S. Boudin, B. Rondot, M. Da Cunha Belo The electronic structure of passive films formed on stainless steels, Corros. Sci. 37 (1995) 1809-1822.

[45] N.E. Hakiki, M. Da Cunha Belo, A. M. P. Simões and M.G.S. Ferreira. Semiconducting Properties of Passive Films Formed on Stainless Steels Influence of the Alloying Elements. J. Electrochem. Soc. 145 (1998) 3821-3829.

[46] Y.X. Qiao, Y.G. Zheng, W. Ke, P.C. Okafor. Electrochemical behaviour of high nitrogen stainless steel in acidic solutions. Corros. Sci. 51 (2009) 979-986.

[47] K. Uosaki, H. Kita. Effects of the Helmholtz Layer Capacitance on the Potential Distribution at Semiconductor/Electrolyte Interface and the Linearity of the Mott - Schottky Plot. J. Electrochem. Soc. 130 (1983) 895-897.

[48] M. Parrinello, A. Rahman. Polymorphic transitions in single crystals: A new molecular dynamics method J. Appl. Phys. 52 (1981) 808-810.

[49] Agatino Di Paola. Semiconducting properties of passive films on stainless steels. Electrochim. Acta 34 (1989) 203-210.

[50] T.L.S Wijesinghe, D.J. Blackwood. Photocurrent and capacitance investigations into the nature of the passive films on austenitic stainless steels, Corros. Sci. 50 (2008) 23-34.

[51] Z. Feng, X. Cheng, C.Dong, L. Xu, X. Li Passivity of 316L stainless steel in borate buffer solution studied by Mott-Schottky analysis, atomic absorption spectrometry and X-ray photoelectron spectroscopy. Corros. Sci. 52 (2010) 36463653.

[52] S. U.M. Khan, W. Schmickler. The capacity of thin passive films. Journal of Electroanalytical Chemistry and Interfacial Electrochemistry, 108 (1980), p. 329-334.

[53] T.L.S Wijesinghe, D.J. Blackwood. Electrochemical and Photoelectrochemical Characterization of the Passive Film Formed on AISI 254SMO Super-Austenitic Stainless Steel J. Electrochem. Soc. 154 (2007) C16-C23.

[54] R.M. Fernández-Domene, E. Blasco-Tamarit, D.M. García-García, J. GarcíaAntón. Passive and transpassive behaviour of Alloy 31 in a heavy brine $\mathrm{LiBr}$ solution. Electrochimica Acta 95 (2013) 1-11. 
[55] D.M. Tencha, E. Yeager. Capacitance Measurements on Lithiated Nickel Oxide Electrodes. J. Electrochem. Soc., 120 (1973), 164-170.

[56] M. Metikoš-Huković, R. Babić, Z. Grubač, Ž. Petrović, N. Lajçi. High corrosion resistance of austenitic stainless steel alloyed with nitrogen in an acid solution. Corros. Sci. 53 (2011) 2176-2183.

[57] A. Shahryari, S. Omanovic. Improvement of pitting corrosion resistance of a biomedical grade 316LVM stainless steel by electrochemical modification of the passive film semiconducting properties. Electrochem. Commun. 9 (2007) 76-82.

[58] L. Pons, M.L. Délia, R. Basséguy, A. Bergel. Effect of the semi-conductive properties of the passive layer on the current provided by stainless steel microbial cathodes. Electrochim. Acta 56 (2011) 2682-2688.

[59] M.J. Carmezim, A.M. Simões, M.F. Montemor, M. Da Cunha Belo. Capacitance behaviour of passive films on ferritic and austenitic stainless steel. Corros. Sci. 47 (2005) 581-591.

[60] M.G.S. Ferreira, N.E. Hakiki, G. Goodlet, S. Faty, A.M.P. Simões, M. Da Cunha Belo. Influence of the temperature of film formation on the electronic structure of oxide films formed on 304 stainless steel Electrochim. Acta 46 (2001) 3767-3776.

[61] N.E. Hakiki. Comparative study of structural and semiconducting properties of passive films and thermally grown oxides on AISI 304 stainless steel. Corros. Sci. 53 (2011) 2688-2699.

[62] P. A Castro, E. R.Vago, E. J. Calvo. Surface electrochemical transformations on spinel iron oxide electrodes in aqueous solutions. Journal of the Chemical Society, Faraday Transactions 92 (1996) 3371-3379.

[63] R. Itai, M. Shibuya, T. Matsumura, G. Ishi, Electrical resistivity of magnetite anodes. J. Electrochem. Soc. 118 (1971) 1709-11.

[64] E.J.W. Verwey, P.W. Haayman. Electronic conductivity and transition point of magnetite (Fe3O4). Physica 8 (1941) 979-987.

[65] Se Jin Ahn, Hyuk Sang Kwon. Effects of solution temperature on electronic properties of passive film formed on $\mathrm{Fe}$ in $\mathrm{pH} 8.5$ borate buffer solution. Electrochim. Acta 49 (2004) 3347-3353.

[66] E. Sikora, J. Sikora, D.D. Macdonald. A new method for estimating the diffusivities of vacancies in passive films. Electrochim. Acta, 41 (1996) 783-789.

[67] Y.X. Qiao, Y.G. Zheng, W. Ke, P.C. Okafor. Electrochemical behaviour of high nitrogen stainless steel in acidic solutions. Corros. Sci. 51 (2009), 979-986.

[68] E. Cho, H. Kwon, D.D. Macdonald. Photoelectrochemical analysis on the passive film formed on $\mathrm{Fe}-20 \mathrm{Cr}$ in $\mathrm{pH} 8.5$ buffer solution. Electrochim. Acta 47 (2002), 1661-1668. 


\section{Table captions}

Table 1. Equivalent circuit parameters obtained by fitting the experimental results of electrochemical impedance spectroscopy measurements, for Alloy 900 in the $1 \mathrm{mM}$ $\mathrm{NaCl}$ solution at different film formation temperatures $\left(700,800\right.$ and $\left.900{ }^{\circ} \mathrm{C}\right)$.

Table 2. Donor densities for Alloy 900 in the $1 \mathrm{mM} \mathrm{NaCl}$ solution at different film formation temperatures $\left(700,800\right.$ and $\left.900{ }^{\circ} \mathrm{C}\right)$.

\section{Figure captions}

Figure 1. In-situ images of the Alloy 900 surface during a heating at $700{ }^{\circ} \mathrm{C}$ for 2 hours in an atmosphere with air.

Figure 2. In-situ images of the Alloy 900 surface during a heating at $800{ }^{\circ} \mathrm{C}$ for 2 hours in an atmosphere with air.

Figure 3. In-situ images of the Alloy 900 surface during a heating at $900{ }^{\circ} \mathrm{C}$ for 2 hours in an atmosphere with air.

Figure 4. Graph of mass gain of Alloy 900 against oxidation temperature after heating the samples 2 hours.

Figure 5. Raman spectra of the oxide films induced on Alloy 900 in the presence of air at $700{ }^{\circ} \mathrm{C}, 800^{\circ} \mathrm{C}$ and $900^{\circ} \mathrm{C}$ after heating the samples 2 hours.

Figure 6. Scanning electron microscopy micrographs of the Alloy 900 morphology after the heat treatments at the different temperatures (backscattered electrons).

Figure 7. Potentiodynamic polarisation curve of Alloy 900 in the $1 \mathrm{mM} \mathrm{NaCl}$ solution at different film formation temperatures $\left(700,800\right.$ and $\left.900^{\circ} \mathrm{C}\right)$.

Figure 8. Nyquist and Bode plots for Alloy 900 in the $1 \mathrm{mM} \mathrm{NaCl}$ solution at different film formation temperatures $\left(700,800\right.$ and $\left.900{ }^{\circ} \mathrm{C}\right)$.

Figure 9. Kramers-Kronig transforms of electrochemical impedance spectroscopy data for Alloy 900 in the $1 \mathrm{mM} \mathrm{NaCl}$ solution heated at $700{ }^{\circ} \mathrm{C}$ for 2 hours.

Figure 10. Equivalent circuit proposed for data shown in Figure 8.

Figure 11. Mott-Schottky plots for Alloy 900 in the $1 \mathrm{mM} \mathrm{NaCl}$ solution obtained at 5 $\mathrm{kHz}$ at different film formation temperatures $\left(700,800\right.$ and $\left.900{ }^{\circ} \mathrm{C}\right)$. 


\begin{tabular}{|c|c|c|c|c|c|c|c|c|c|}
\hline$T\left({ }^{\circ} \mathrm{C}\right)$ & $\begin{array}{c}R_{S} / \mathbf{k} \boldsymbol{\Omega} \\
\mathbf{c m}^{2}\end{array}$ & $C_{1} / \mu \mathrm{F} \mathrm{cm}^{-2}$ & $\alpha_{1}$ & $R_{I} / \mathrm{k} \Omega \mathrm{cm}^{2}$ & $C_{2} / \mu \mathrm{F} \mathrm{cm}$ & $\alpha_{2}$ & $R_{2} / \mathrm{k} \Omega \mathrm{cm}^{2}$ & $\begin{array}{c}R_{p} / \mathrm{k} \Omega \\
\mathrm{cm}^{2}\end{array}$ & $\chi^{2}\left(\mathbf{x 1 0 ^ { - 3 }}\right)$ \\
\hline 700 & $0.9 \pm 0.0$ & $0.30 \pm 0.07$ & $0.64 \pm 0.08$ & $1.0 \pm 0.0$ & $6 \pm 3$ & $0.70 \pm 0.04$ & $899 \pm 21$ & 900 & 0.6 \\
\hline 800 & $1.0 \pm 0.1$ & $0.70 \pm 0.08$ & $0.73 \pm 0.02$ & $1.1 \pm 0.1$ & $86 \pm 2$ & $0.80 \pm 0.07$ & $607 \pm 28$ & 608 & 1.5 \\
\hline 900 & $1.2 \pm 0.1$ & $0.28 \pm 0.03$ & $0.42 \pm 0.00$ & $31.1 \pm 1.1$ & $41 \pm 3$ & $0.88 \pm 0.04$ & $296 \pm 56$ & 328 & 0.5 \\
\hline
\end{tabular}


Tables 2

\begin{tabular}{|c|c|}
\hline Film (Temperature) & $\mathbf{N}_{\mathbf{D}}\left(\mathbf{x 1 0} \mathbf{2 0}^{\mathbf{2 0}} \mathbf{c m}^{\mathbf{- 3}}\right)$ \\
\hline $700{ }^{\circ} \mathrm{C}$ & $8.7 \pm 0.5$ \\
\hline $800^{\circ} \mathrm{C}$ & $7.8 \pm 0.1$ \\
\hline $900^{\circ} \mathrm{C}$ & $4.5 \pm 0.2$ \\
\hline
\end{tabular}




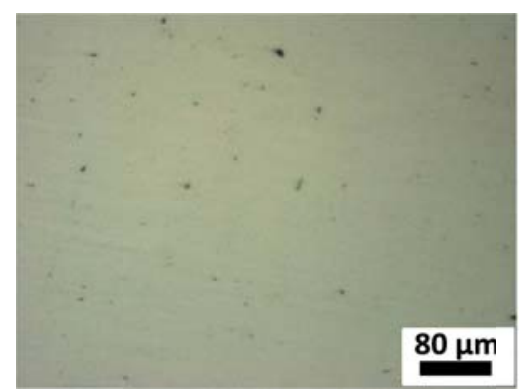

a) $25^{\circ} \mathrm{C}$

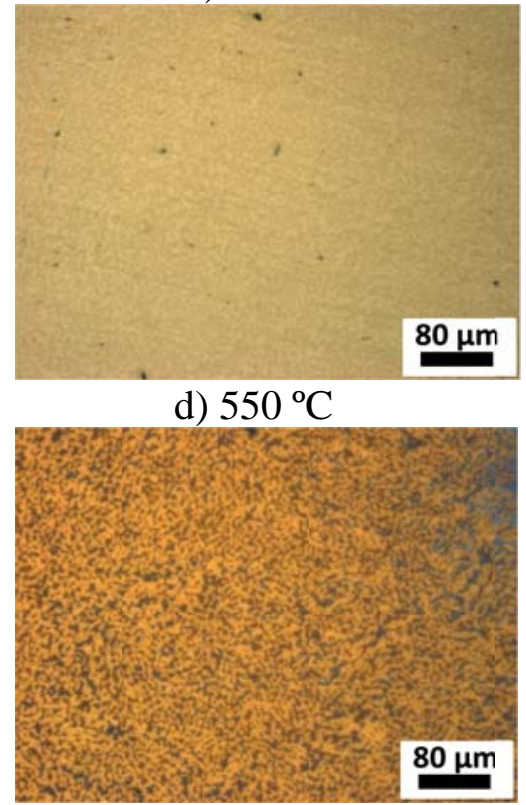

g) $700{ }^{\circ} \mathrm{C}, 20$ minutes

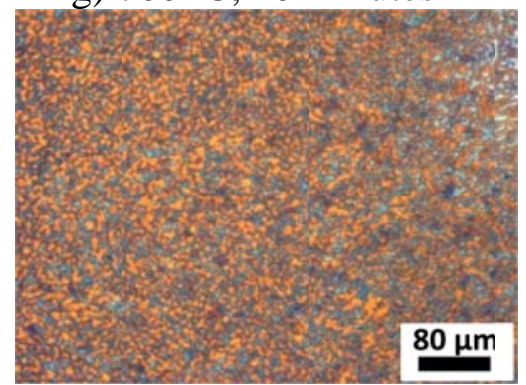

j) $700{ }^{\circ} \mathrm{C}, 80$ minutes

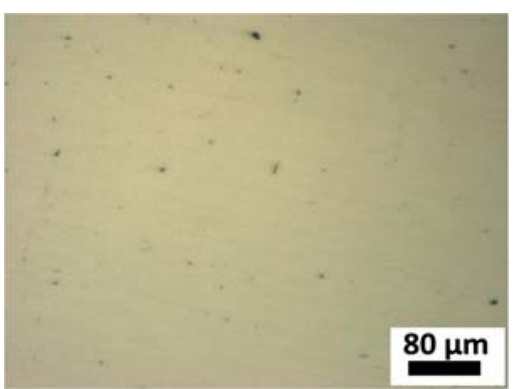

b) $350{ }^{\circ} \mathrm{C}$

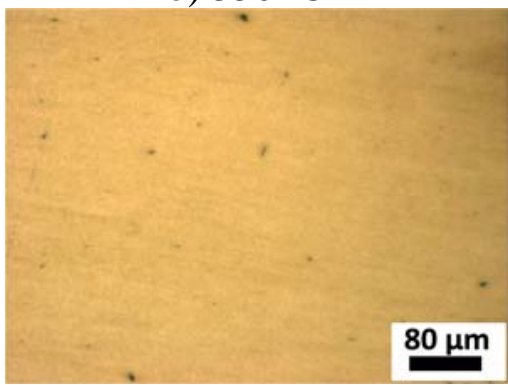

e) $650{ }^{\circ} \mathrm{C}$

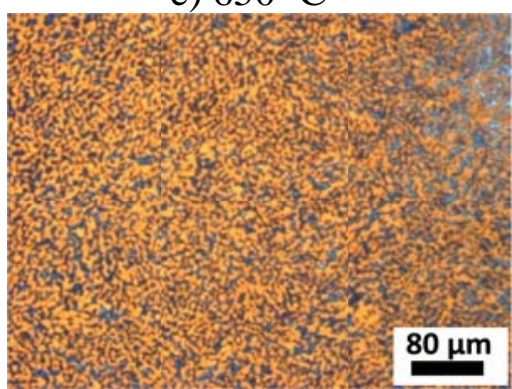

h) $700{ }^{\circ} \mathrm{C}, 40$ minutes

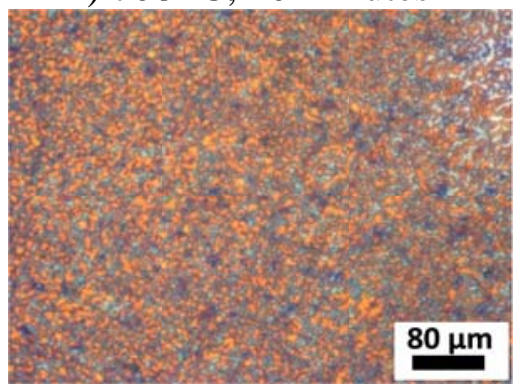

k) $700{ }^{\circ} \mathrm{C}, 100$ minutes

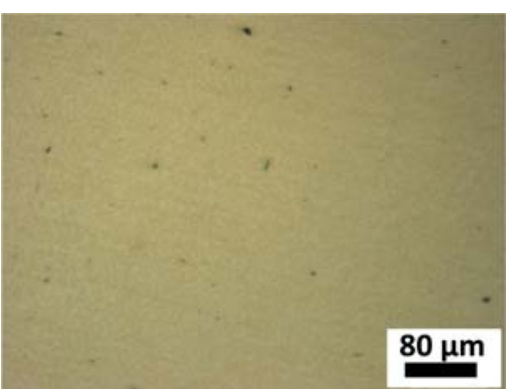

c) $450{ }^{\circ} \mathrm{C}$

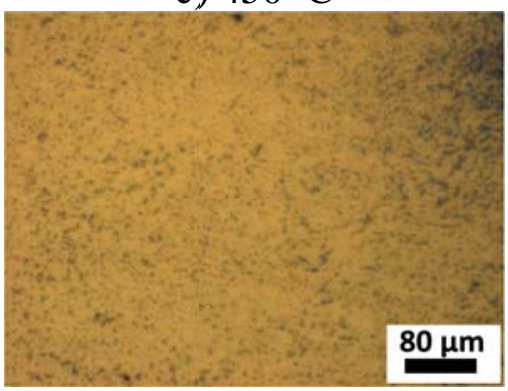

f) $700{ }^{\circ} \mathrm{C}, 1$ minutes

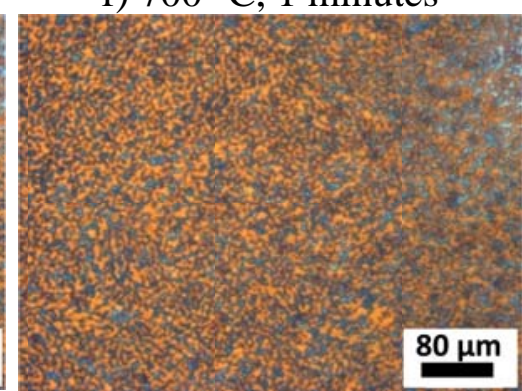

i) $700{ }^{\circ} \mathrm{C}, 60$ minutes

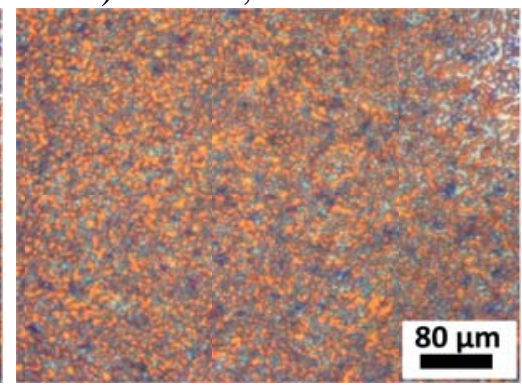

k) $700{ }^{\circ} \mathrm{C}, 120$ minutes 
Click here to download Figures (if any): Figure 2.pdf

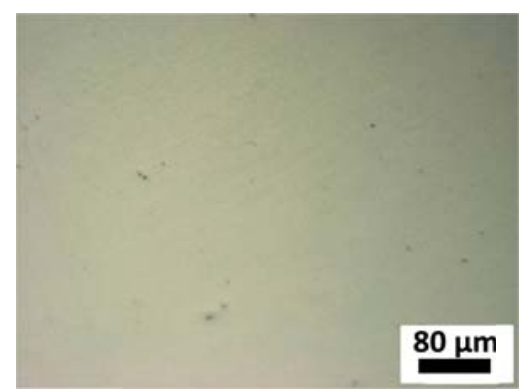

a) $25^{\circ} \mathrm{C}$

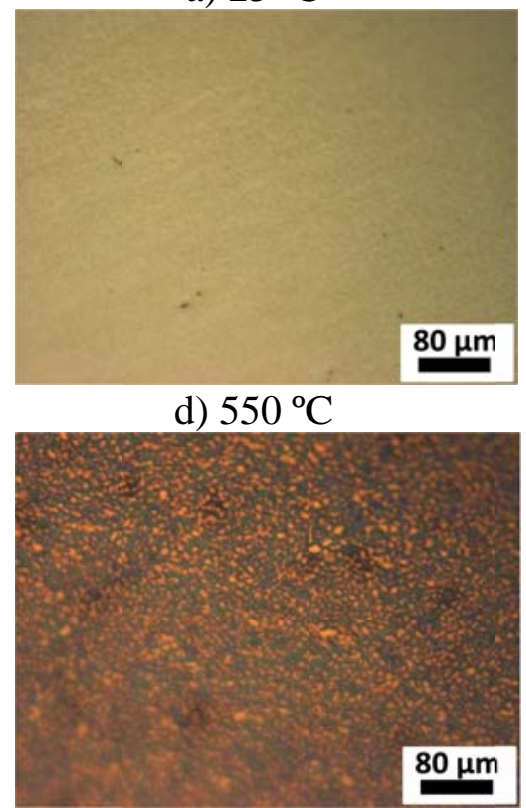

g) $800{ }^{\circ} \mathrm{C}, 10$ minutes

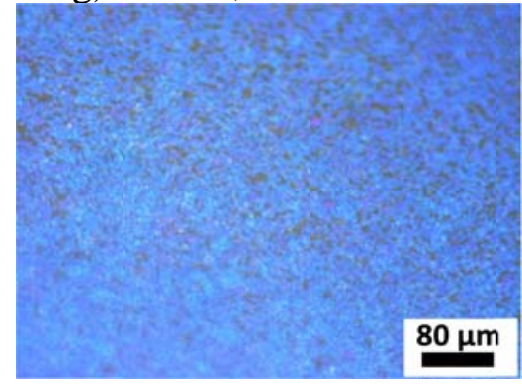

j) $800^{\circ} \mathrm{C}, 50$ minutes

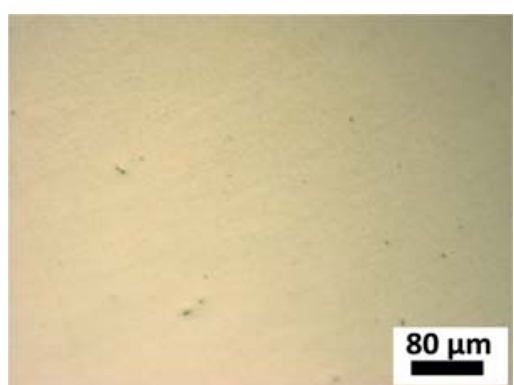

b) $375{ }^{\circ} \mathrm{C}$

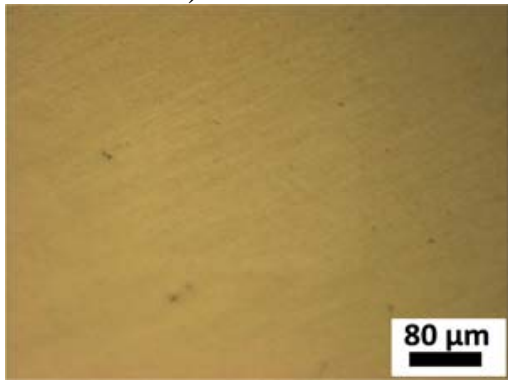

e) $710^{\circ} \mathrm{C}$

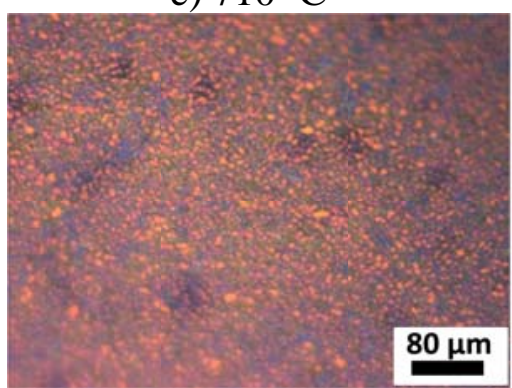

h) $800{ }^{\circ} \mathrm{C}, 15$ minutes

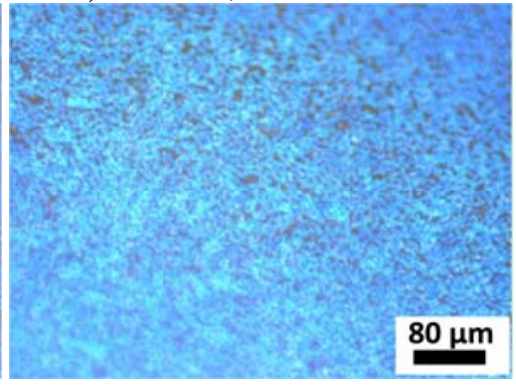

k) $800^{\circ} \mathrm{C}, 90$ minutes

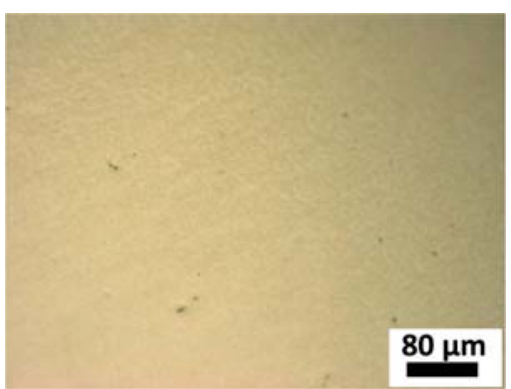

c) $450{ }^{\circ} \mathrm{C}$

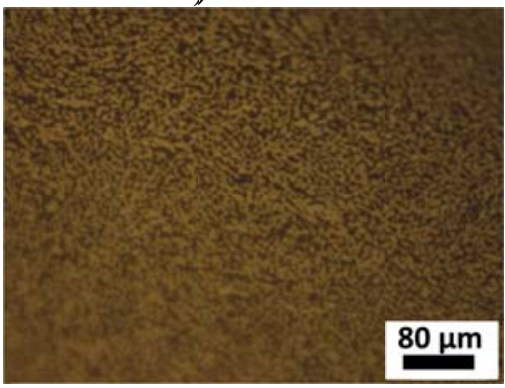

f) $800{ }^{\circ} \mathrm{C}, 1$ minutes

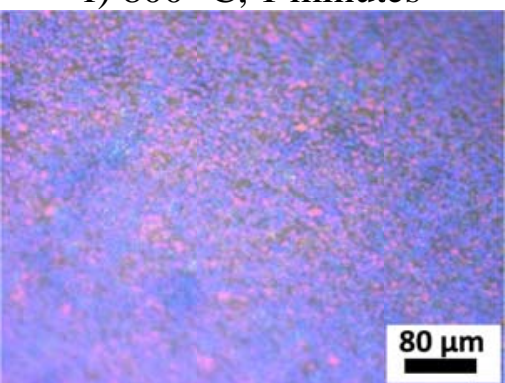

i) $800{ }^{\circ} \mathrm{C}, 30$ minutes

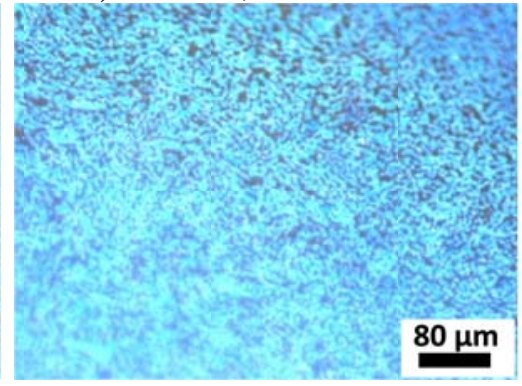

l) $800{ }^{\circ} \mathrm{C}, 120$ minutes 
Figures 3

Click here to download Figures (if any): Figure 3.pdf

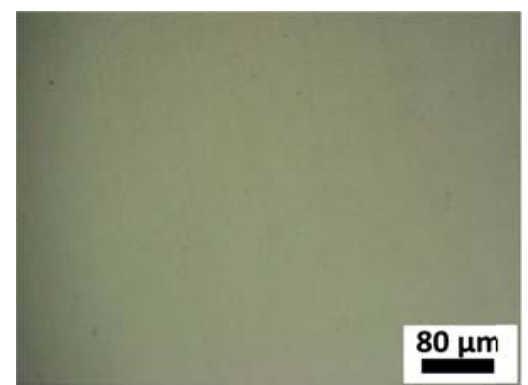

$80 \mu \mathrm{m}$

a) $25^{\circ} \mathrm{C}$

b) $450{ }^{\circ} \mathrm{C}$

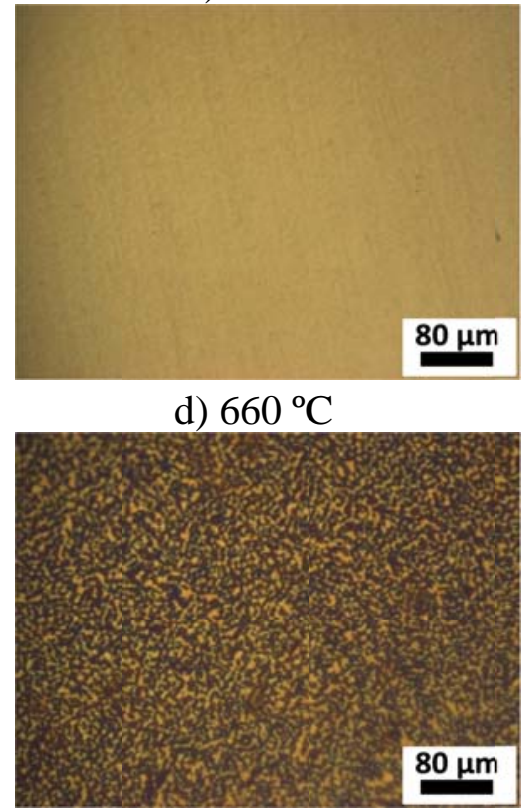

g) $900^{\circ} \mathrm{C}, 1$ minute

e) $730{ }^{\circ} \mathrm{C}$

$80 \mu \mathrm{m}$
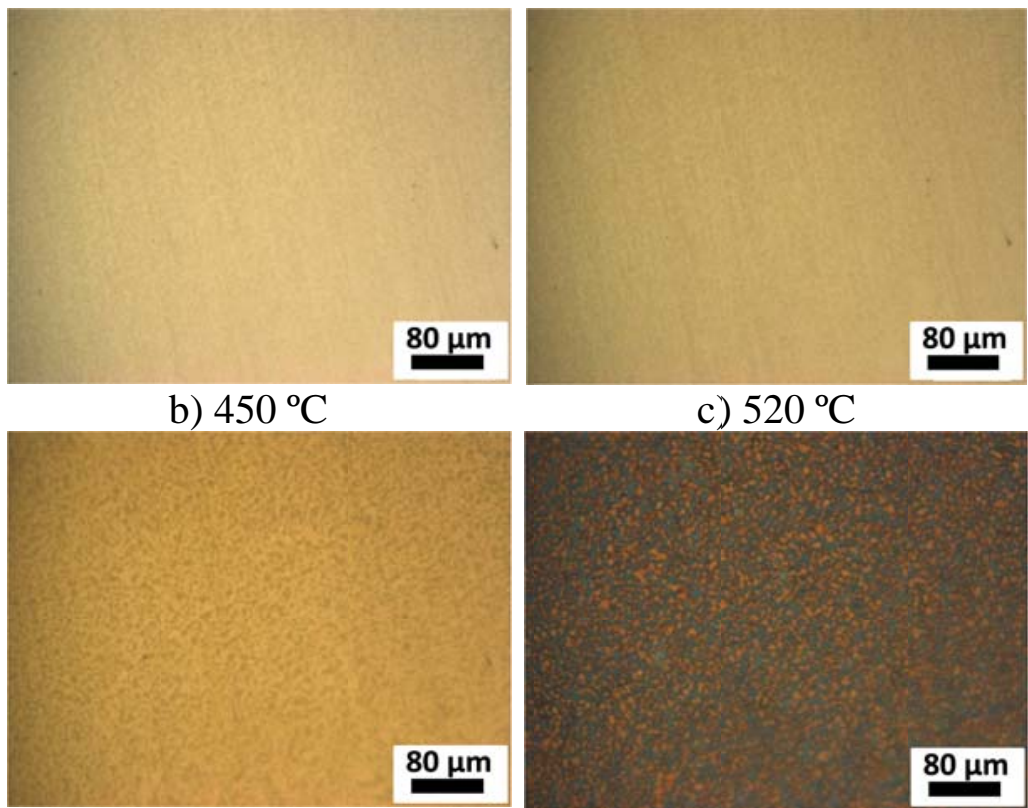

c) $520^{\circ} \mathrm{C}$

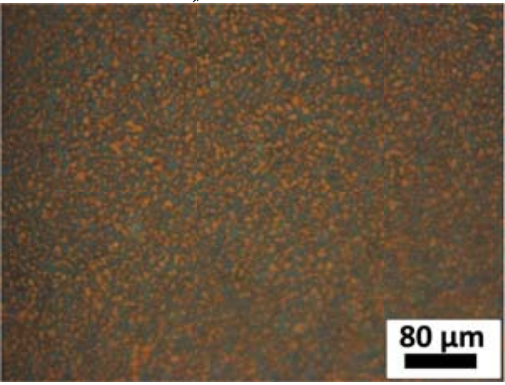

f) $850{ }^{\circ} \mathrm{C}$

$80 \mu \mathrm{m}$

$80 \mu \mathrm{m}$

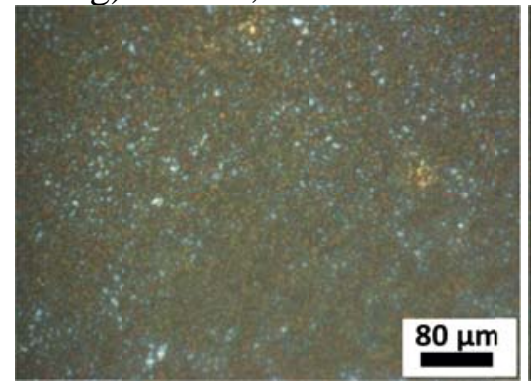

h) $900{ }^{\circ} \mathrm{C}, 10$ minutes

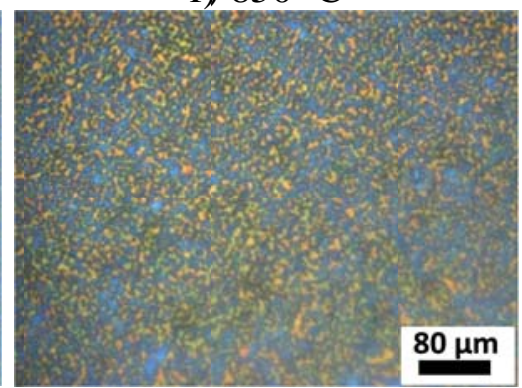

i) $900{ }^{\circ} \mathrm{C}, 20$ minutes

j) $900^{\circ} \mathrm{C}, 40$ minutes

k) $900{ }^{\circ} \mathrm{C}, 80$ minutes

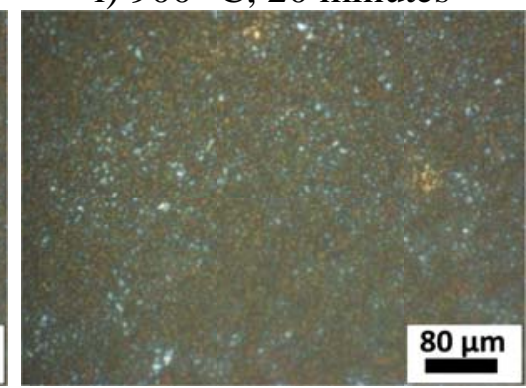

l) $900{ }^{\circ} \mathrm{C}, 120$ minutes 


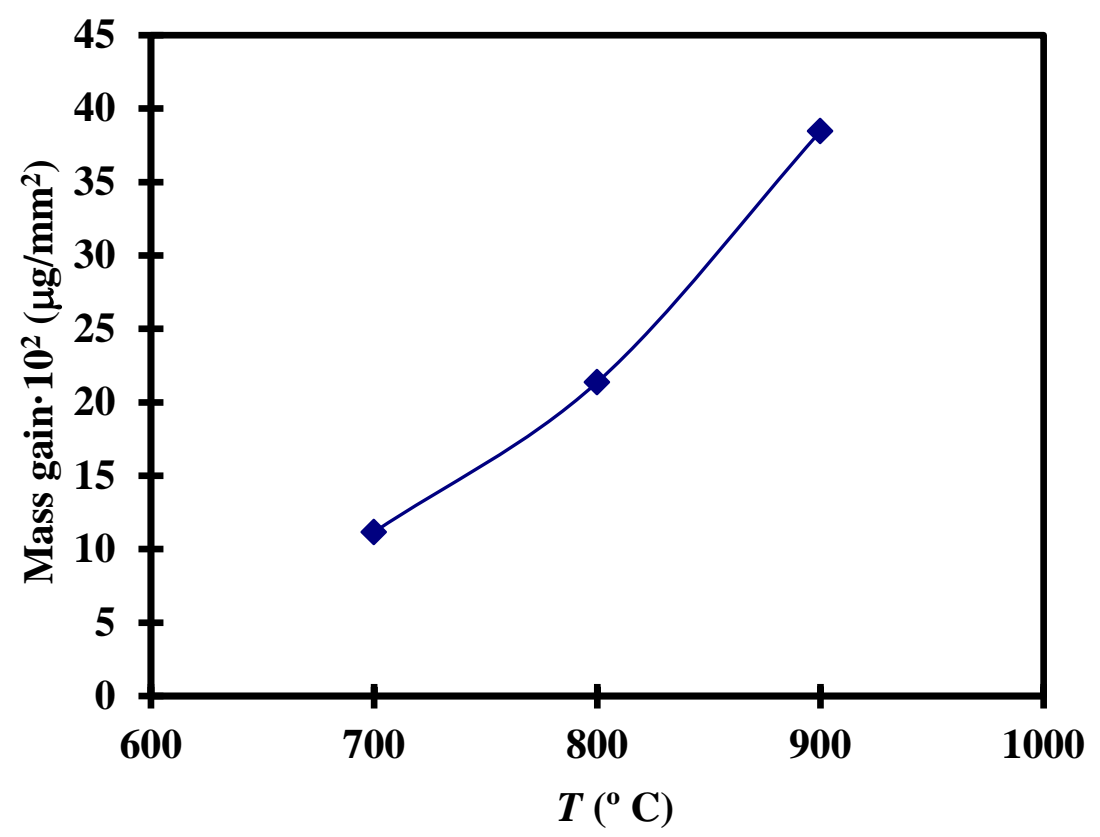

Figure 4. Graph of mass gain of Alloy 900 against oxidation temperature. 

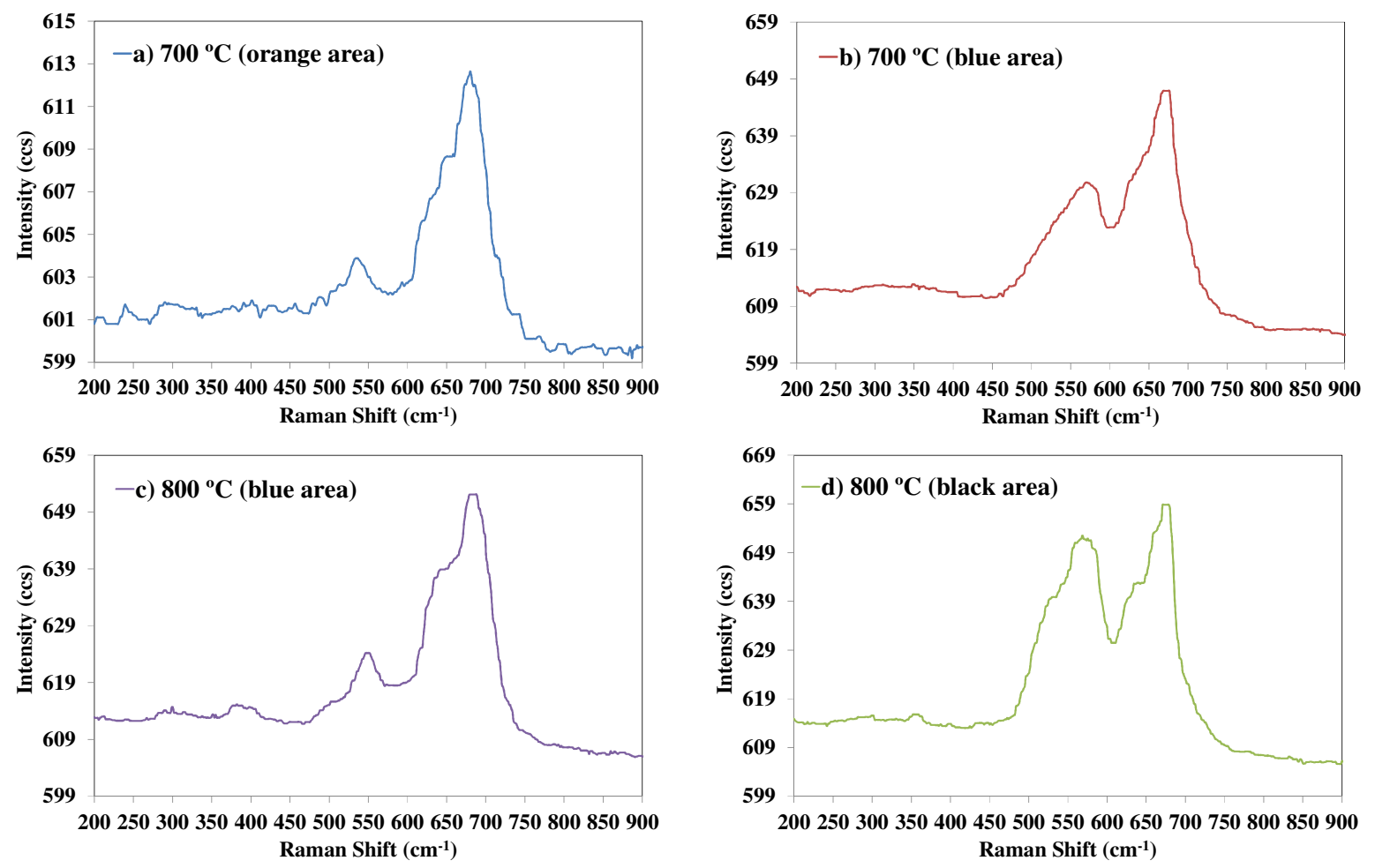
Raman Shift $\left(\mathrm{cm}^{-1}\right)$

$$
\text { Raman Shift }\left(\mathbf{c m}^{-1}\right)
$$

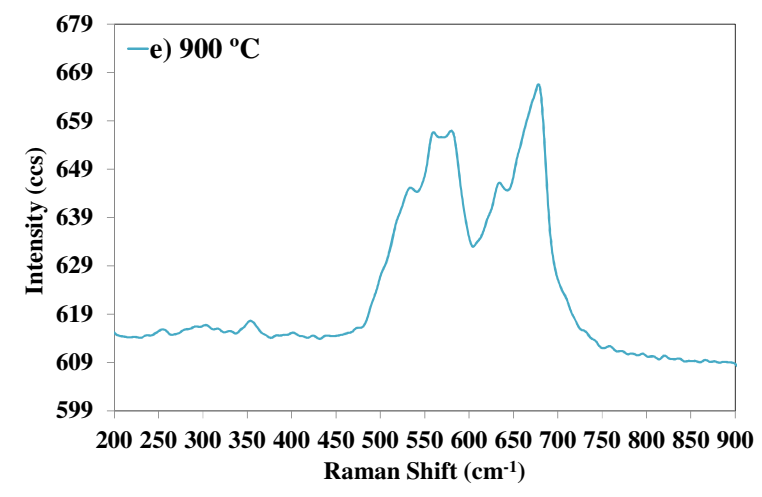


Figures 6

Click here to download Figures (if any): Figure 6.pdf

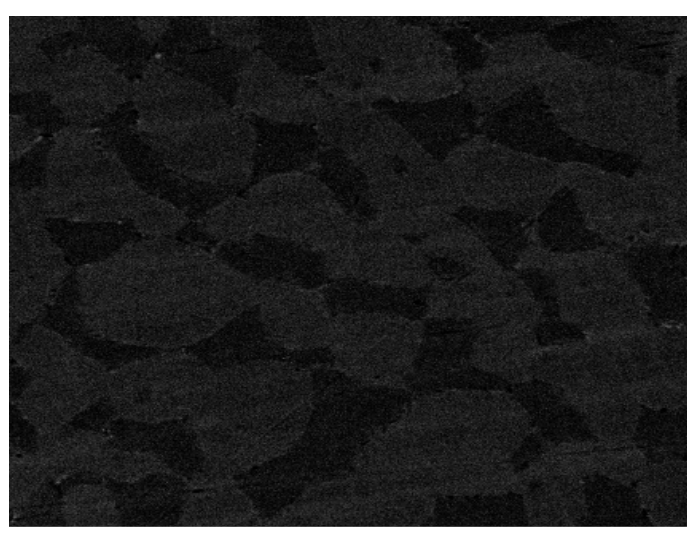

$30 \mu \mathrm{m}$

$700{ }^{\circ} \mathrm{C}, 2$ hours

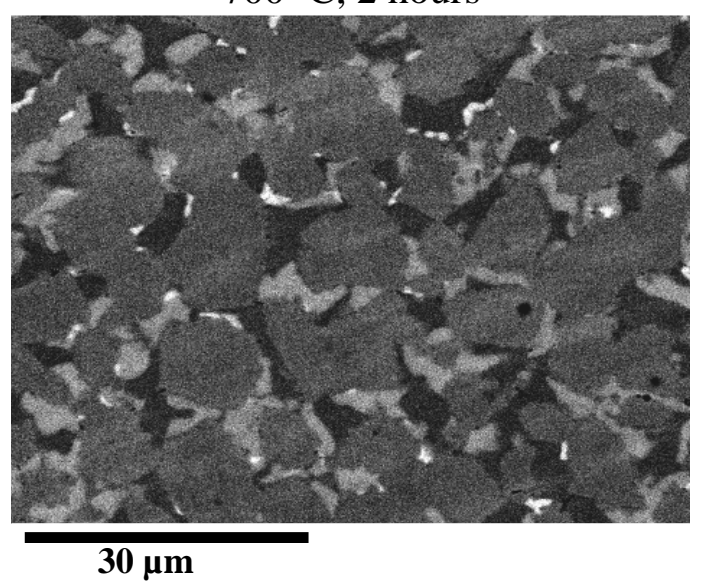

$800^{\circ} \mathrm{C}, 2$ hours

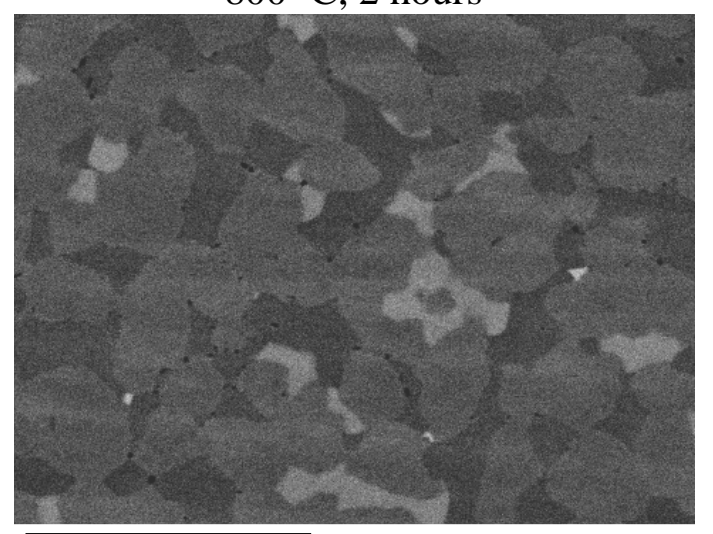

$30 \mu \mathrm{m}$

$900^{\circ} \mathrm{C}, 2$ hours 


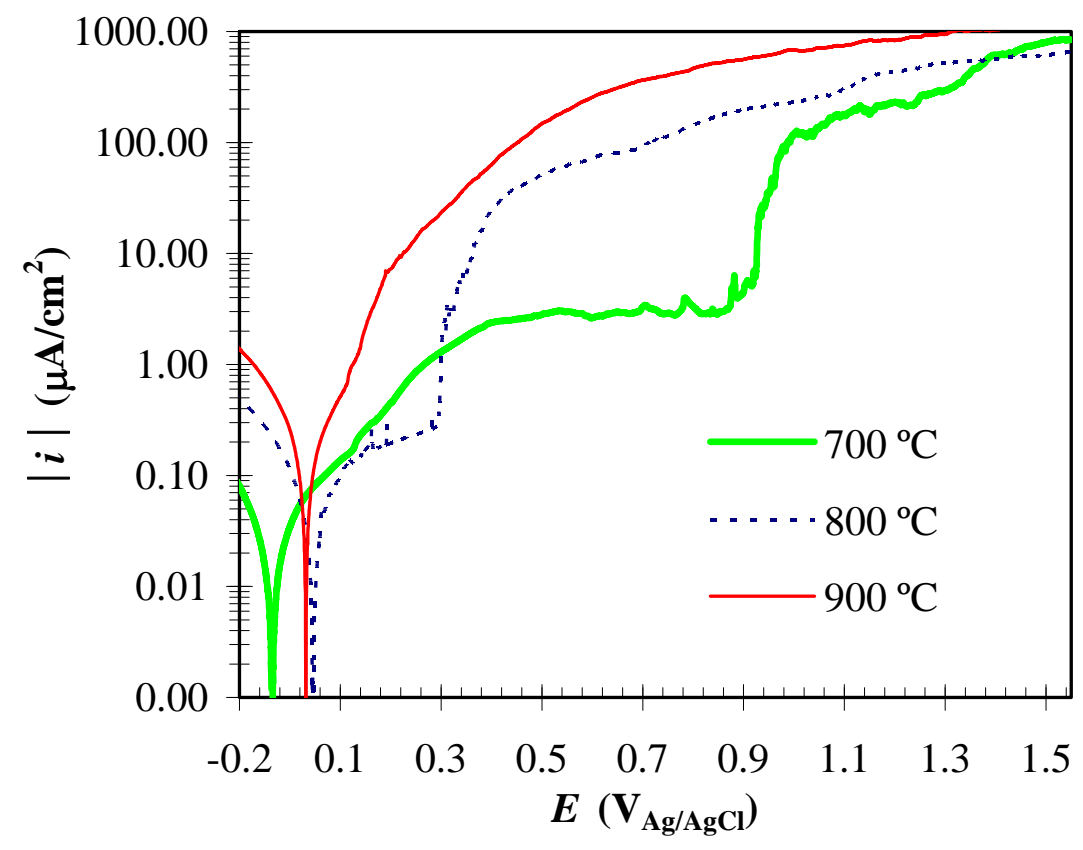


a
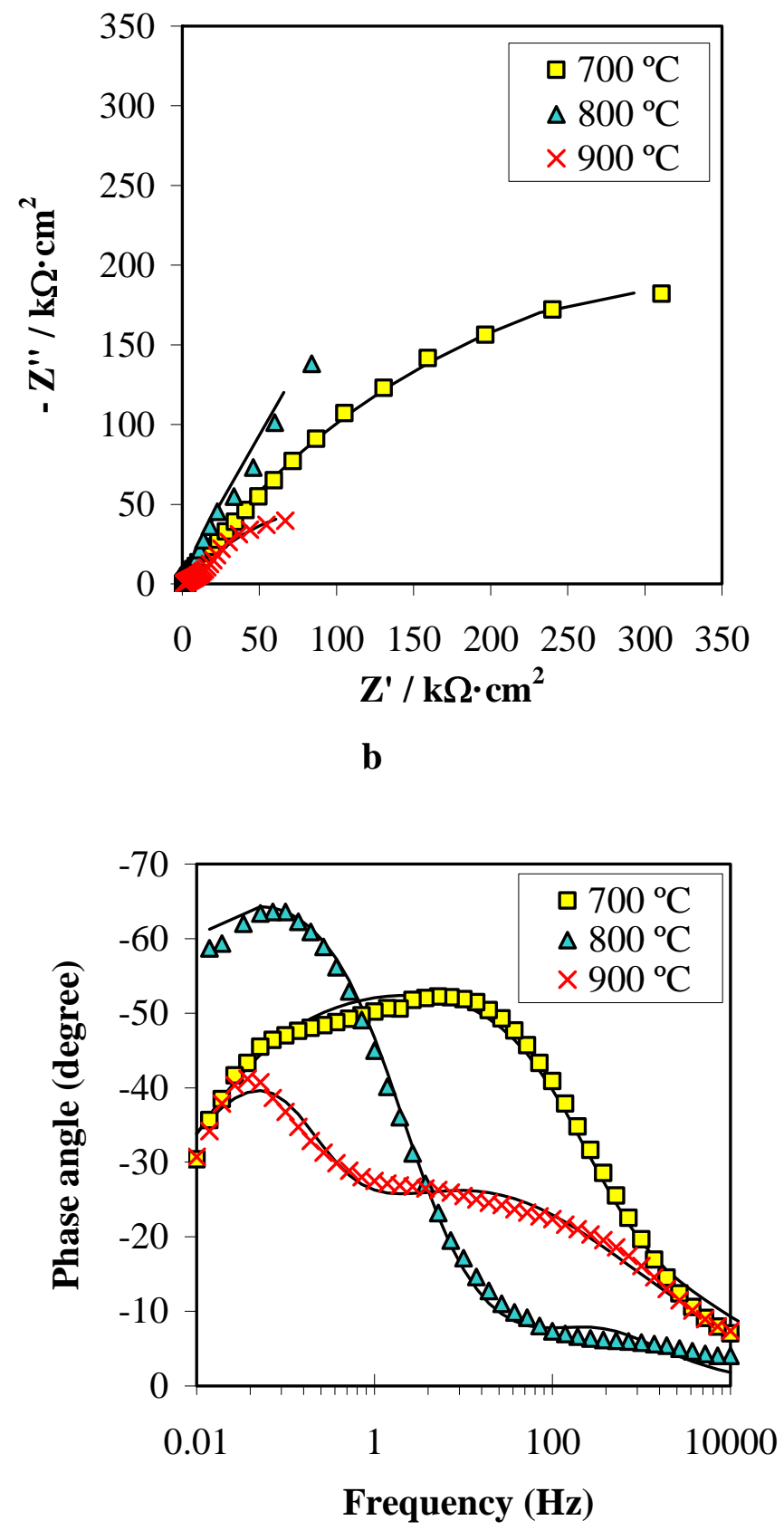


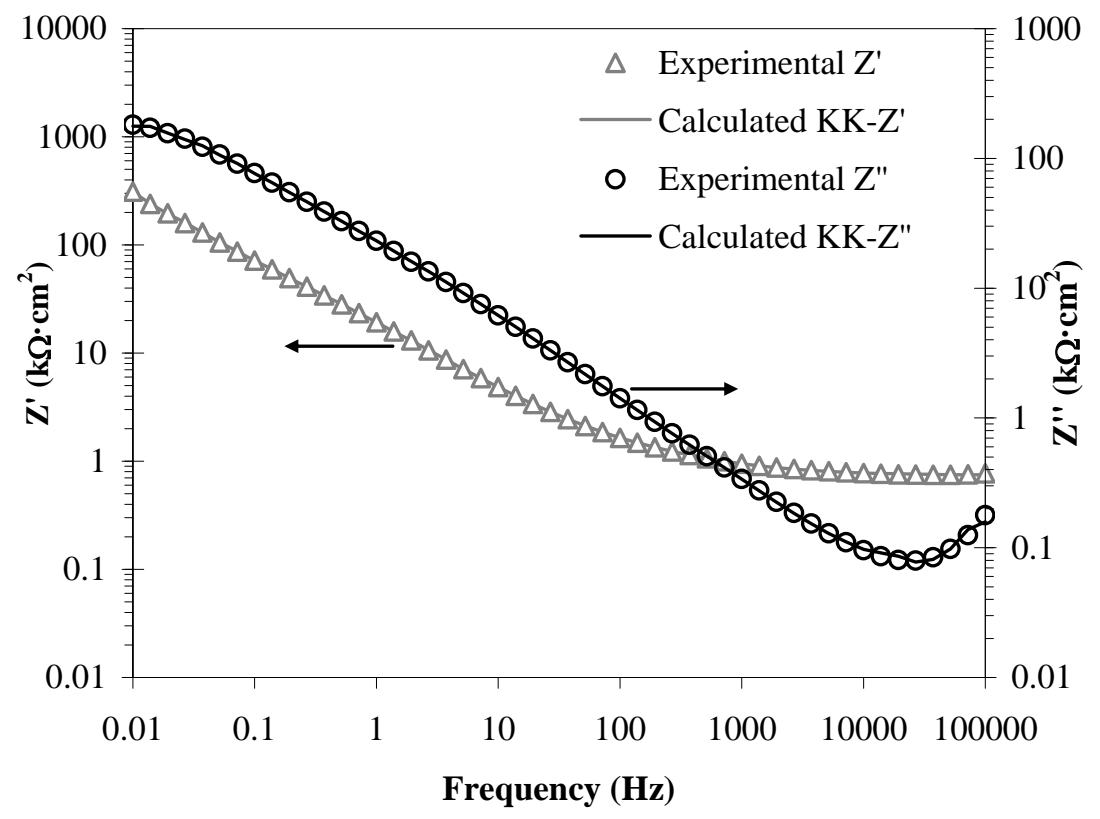


Figures 10
Click here to download Figures (if any): Figure 10.pdf

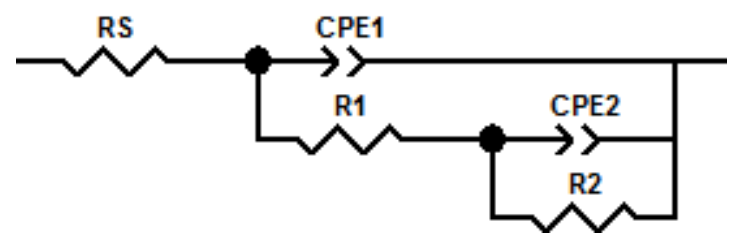




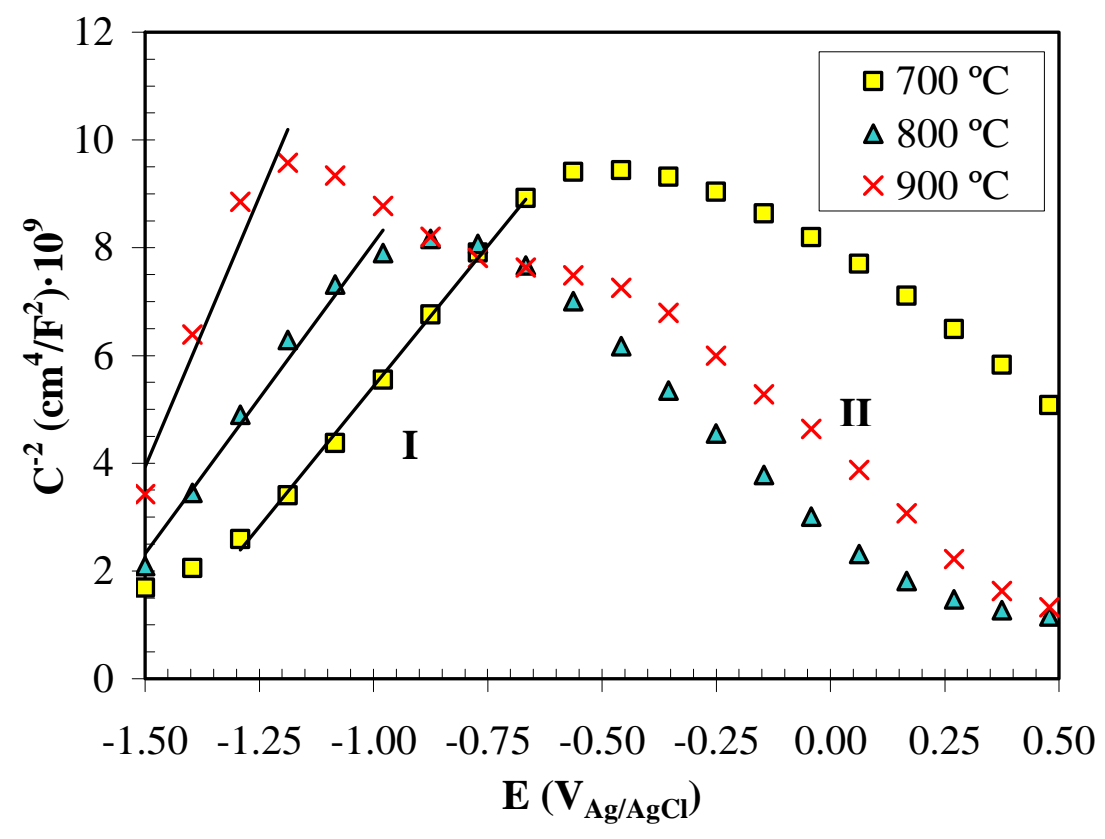

